\title{
Seismic analysis and design of steel-plate concrete composite shear wall piers
}

\author{
Siamak Epackachi ${ }^{1}$, Andrew S. Whittaker ${ }^{2}$, and Amjad Aref ${ }^{3}$
}

\section{Abstract}

This paper presents results of numerical studies on the in-plane monotonic response of steel-plate concrete (SC) composite shear wall piers. Results of finite element analysis of $98 \mathrm{SC}$ wall piers are used to investigate the effects of wall aspect ratio, reinforcement ratio, slenderness ratio, axial load, yield strength of the steel faceplates, and uniaxial compressive strength of concrete on in-plane response, and to formulate a) predictive equations to establish the trilinear lateral force versus lateral displacement response of SC wall piers up to peak strength, sufficient for seismic analysis of structures including SC wall piers, and b) a mechanics-based design equation for peak flexural strength, which addresses the interaction of co-existing shear and axial force. Design of Experiments is used to select the 98 piers. The baseline finite element model was formally validated using data from reversed cyclic, inelastic in-plane tests of four large-scale SC wall piers.

Key words: Steel-plate composite shear wall, analytical model, infill concrete, steel faceplate, mechanics-based equation, statistical predictive models, LS-DYNA.

\section{Introduction}

Steel-plate concrete (SC) composite shear walls used or proposed for construction in the United States are constructed using steel faceplates, infill concrete, and connectors used to anchor the steel faceplates together and to the infill concrete. Although the seismic behavior of SC walls has been studied in some detail over the past 25+ years [1-20], the number of applications to date has been limited. Empirical equations to predict the initial stiffness and

\footnotetext{
${ }^{1}$ Teaching Assistant Professor, Dept. of Civil, Structural and Environmental Engineering, University at Buffalo, NY (siamakep@buffalo.edu)

${ }^{2}$ Professor; Director, MCEER; Dept. of Civil, Structural and Environmental Engineering, University at Buffalo, NY

${ }^{3}$ Professor, Dept. of Civil, Structural and Environmental Engineering, University at Buffalo, NY
} 
23 lateral load capacity of SC walls have been proposed, but effects of key design variables,

24 including wall aspect ratio, reinforcement and slenderness ratios, axial load, and material

25 properties have not been systemically accounted for. Herein, these design variables are addressed 26 explicitly to

27 - Develop predictive equations to fully characterize the trilinear seismic response of an SC equations to characterize trilinear response and the mechanics-based equation for peak flexural strength. The literature review that follows immediately below focuses on those studies that address the behavior of SC wall piers considering one or more of the key design variables listed 35 above.

\section{Literature Review}

Fukumoto et al. [21] tested 1/4-scale steel plate, plain concrete, and composite shear walls under axial and shear loads to study the effects of composite action between the steel 39 faceplates and the infill concrete, slenderness ratio, and stiffening methods for the steel faceplates, on the response of SC walls. The composite walls were constructed by assembling

41 welded steel boxes and infilling them with concrete: different from the construction discussed 42 above. Qualitative conclusions were drawn but they were by-and-large specific to the construction used.

Takeda et al. [22] subjected seven composite wall panels to in-plane cyclic loading in 
47 composed of two steel faceplates, infill concrete, headed steel studs anchoring the faceplates to

48 the infill, and the partitioning webs joining the steel faceplates: somewhat different to the

49 construction discussed above. The results of the Takeda study indicated that stud spacing, in the

50 range considered, had no effect on peak strength. These authors parsed the pre-peak-strength

51 response into four regions: 1) elastic, 2) post-concrete cracking, 3) post-buckling of steel

52 faceplates, and 4) post-yielding of steel faceplates. The shear response of these SC panels was

53 idealized using a perfectly plastic force-displacement relationship because their lateral load

54 capacity did not deteriorate at shear strains less than $2 \%$.

55 Sasaki et al. [23] tested seven flanged walls with aspect ratios ranging between 0.33 and

560.5 to investigate the effects of aspect ratio, reinforcement ratio, axial load, and the use of headed

57 studs attached to the end plates of the web wall on the flexural-shear response of SC walls. A

58 faceplate slenderness ratio of 33 was used. They reported the lateral stiffness and strength of a

59 flanged SC walls increase with decreasing shear span-to-depth ratio and increasing

60 reinforcement ratio, which is somewhat intuitive. Increases in axial load led to an increase in

61 lateral strength but not initial stiffness.

62 Ozaki et al. [14] tested flanged walls with different aspect and reinforcement ratios under

63 lateral loading to investigate the in-plane response of shear-critical and flexure-critical SC walls.

64 Five shear-critical SC specimens with aspect ratios ranging from 0.5 to 0.85 and reinforcement

65 ratios ranging from $0.7 \%$ to $2 \%$ were tested. The reinforcement ratio had a small effect on the

66 initial stiffness and cracking strength of the shear-critical SC walls but it significantly affected

67 the yield and the peak lateral loads. The displacements corresponding to the yield and lateral

68 loads were not affected by reinforcement ratio. Four flexure-critical SC walls with aspect ratios

69 of 0.7 and 0.85 , and a reinforcement ratio of $2 \%$, were also tested. The design parameters 
70 considered in this part of their study were aspect ratio, axial force, and type of SC wall

71 connection to the foundation. Ozaki et al. proposed that the bending strength of flexure-critical

72 SC walls be calculated using the results of plastic cross-section analysis. The interaction of axial

73 force and bending moment was ignored.

74 Nie et al. [24] subjected twelve walls to axial and cyclic lateral loads to investigate the 75 effects of reinforcement ratio, concrete strength, thicknesses of the steel face and flange plates, 76 concrete reinforcement, and wall aspect ratio on the in-plane response of SC walls. The 77 reinforcement and aspect ratios varied from $4.6 \%$ to $7.1 \%$, and from 1 to 2 , respectively. The 78 twelve specimens failed in flexure, characterized by local buckling and fracture of the steel 79 faceplates. Their test results showed that peak strength increased as shear span-to-depth ratio 80 decreased. Changes in the concrete compressive strength had little effect on the stiffness of the 81 SC specimens.

82 Kurt et al. [12] reported the effects of wall aspect ratio, wall thickness, and reinforcement 83 ratio on the monotonic response of SC wall piers. The finite element codes ABAQUS [25] and 84 LS-DYNA were used for the numerical simulations. Data from tests of eight SC wall piers [10, 85 12] and the numerical simulations were used to derive design equations for the lateral load 86 capacity of SC wall piers. The proposed equation for in-plane flexural capacity is parsed by 87 aspect ratio (ratio of height to length): 1) for aspect ratios of 0.5 and smaller, the capacity is 88 equal to the moment corresponding to the onset of yielding of the steel faceplates at the 89 compression end of the wall, and 2) for aspect ratios of 1.5 and greater, the capacity is equal to 90 the plastic moment capacity of the wall cross-section. The flexural capacity for intermediate 91 aspect ratios is determined by linear interpolation but accounts for wall thickness. The effects of 92 co-existing axial and shearing forces on flexural capacity are not addressed. 


\section{Parametric Study on SC Wall Piers}

A research project was completed at the University at Buffalo in 2013 that investigated the seismic performance of SC composite wall piers for application to buildings and missioncritical infrastructure $[8,10]$. The SC walls considered in that study were composed of two steel faceplates and infill concrete: the construction introduced at the beginning of this paper. The steel faceplates were connected together and to the infill concrete using tie rods and headed studs, respectively. The research project, including an experimental program followed by numerical and analytical studies, focused on the in-plane behavior of flexure- and flexure-shearcritical SC wall piers. In the experimental program, four large-size specimens with an aspect ratio (height-to-length) of 1.0 were tested under displacement-controlled cyclic loading. The design variables were wall thickness, reinforcement ratio, and slenderness ratio. The walls were flexure-critical. A robust finite element model was developed in LS-DYNA for the simulation of the reversed cyclic, inelastic in-plane behavior of the flexure-critical SC walls [26]. The LSDYNA model was formally validated for in-plane response calculations using the results of cyclic tests of SC wall piers. The test data also were used to develop simplified analytical models suitable for preliminary analysis and design of SC walls [11]. In the study reported in this paper, this validated LS-DYNA model for reversed cyclic, inelastic in-plane loading is used to conduct a parametric study on the in-plane monotonic response of SC walls. The results of the parametric study are used to systematically investigate the effects of design variables on the monotonic response of SC wall piers and to derive equations that characterize the trilinear lateral forcedisplacement relationship for an SC wall pier, all as described below.

The design variables considered in this study are: wall aspect ratio (AR), reinforcement ratio (RR), slenderness ratio of the steel faceplates (SR), axial load ratio (AL), yield strength of the steel faceplates (SS), and concrete compressive strength (CS). The reinforcement ratio is 
117 defined as the ratio of the cross-sectional area of the steel faceplates to the total cross-sectional

118 area of SC wall. The faceplate slenderness ratio is the spacing of the connectors (studs or tie

119 rods) divided by the steel faceplate thickness. The axial load ratio is the ratio of the applied axial

120 compressive force to the product of the concrete compressive strength and the total wall area

121 (i.e., $\left.\left(2 t_{s}+t_{c}\right) L\right)$.

Information on the finite element analysis, and the results of the Analysis of Variance

123 (ANOVA), and derivations of the predictive equations are presented in the following sub-

124 sections.

\section{4. Finite element analysis of SC walls}

The general purpose finite element code LS-DYNA [27, 28] was used to conduct the

127 numerical study. The validated numerical model of the SC wall pier for calculations of reversed

128 cyclic, inelastic in-plane response is summarized below. Detailed information on the finite

129 elements, mesh sizes and related convergence studies, and formulations adopted can be found in $130[9,26]$. Two features of the model are a) use of the Winfrith constitutive model that enables

131 shear-force transfer across cracks, opening and closing of cracks, loss of strength and stiffness in 132 the direction parallel to cracks, and tension stiffening, and (b) a contact algorithm to consider 133 friction between the infill concrete and the steel faceplates, and to avoid penetration of concrete 134 through steel, and vice-versa, using a penalty-based approach.

The Winfrith concrete model in LS-DYNA (MAT085), developed by Broadhouse [26],

136 was used for the infill concrete. In this study, three levels (i.e., low-, intermediate-, and high137 levels) were considered for the yield strength of the steel faceplates and concrete compressive 138 strength. Concrete compressive strengths of $27.5 \mathrm{MPa}, 42 \mathrm{MPa}$, and $55 \mathrm{MPa}$ were used to 139 represent low, intermediate, and high values of compressive strength, respectively. The material 
140 properties for the concrete compressive strengths input to the LS-DYNA model are presented in

141 Table 1. Young's modulus for concrete was calculated using Equation 19.2.2.1(b) of ACI 318-14

142 [29]: 4700 $\sqrt{f_{c}^{\prime}}$. The tensile strength and fracture energy of the concrete were calculated per

143 Sections 2.1.3.3.1 and 2.1.3.3.2 of [30], respectively, assuming an aggregate size of $19 \mathrm{~mm}$ for

144 all concrete grades. The crack width was calculated using Equation (3).

145 The Piecewise-Linear-Plasticity model in LS-DYNA (MAT024) was used for the steel

146 faceplates and connectors. Plate steel of ASTM A36 $\left(f_{y}=235 \mathrm{MPa}\right), \mathrm{A} 588\left(f_{y}=350 \mathrm{MPa}\right)$,

147 and $\mathrm{A} 852\left(f_{y}=460 \mathrm{MPa}\right)$ were used to represent low, intermediate, and high values of yield

148 strength, respectively. Figure 1 presents the stress-strain relationships assumed for the ASTM

149 A36, A588, A852 steels used for the steel faceplates. The nominal yield and ultimate strengths of

150 the studs and tie rods were assumed to be 345 and $450 \mathrm{MPa}$, respectively, and not varied for the

151 analysis. The material properties input to LS-DYNA for the different grades of steel are

152 presented in Table 2.

153 Studies in the literature report values for the coefficient of friction between steel and

154 concrete between 0.2 to 0.7 (e.g., Baltay et al. [31], Rabbat et al. [32], Han et al. [33], and Moon

155 et al. [34]). Of these studies, the second is the most relevant to the studies reported here. Rabbat

156 et al. [32], tested 15 concrete blocks cast on steel plates: similar to the SC wall construction

157 investigated here. Their results indicated that the coefficient of friction between flat steel and

158 cast-in-place concrete varied between 0.57 and 0.7. Herein, the coefficient of friction between

159 the steel faceplates and infill concrete was set to the lowest value in the range $(=0.57)$ of Rabbat 160 et al. Importantly, the effect of friction between steel faceplates and infill concrete on the in-

161 plane global response of SC wall piers was previously shown by the authors [26] to be 162 negligible, because the normal stresses acting on the interface were tiny. 

DYNA [27] was used to model the friction between the infill concrete and the steel faceplates. The CONSTRAINED-LAGRANGE-IN-SOLID formulation available in LS-DYNA [27] was used to tie the studs and tie rods to the infill concrete elements.

The studs and tie rods were modeled using beam elements. The infill concrete and the steel faceplates were modeled using $25.4 \times 25.4 \times 25.4 \mathrm{~mm}$ eight-node solid elements and $25.4 \times$ $25.4 \mathrm{~mm}$ four-node shell elements, respectively $[9,26]$. The constant stress formulation (ELFORM=1 in LS-DYNA [27] and Belytschko-Tsay formulation are used for solid elements 171 and shell elements, respectively. The cross section integrated beam element (Hughes-Liu beam 172 in LS-DYNA [27]) is used for the connectors. The LS-DYNA models of the SC walls are 173 presented in Figure 2.

The length and the thickness of the walls were set to $1524 \mathrm{~mm}$ and $304.8 \mathrm{~mm}$, 175 respectively, to enable comparison with experimental results [8-10]. The heights of the SC walls 176 were selected to achieve the targeted aspect ratios, ranging from 0.3 to 3.0.

\section{Parametric study of SC walls using ANOVA}

A Design of Experiments (DOE) [35] was used to effectively and efficiently explore the

179 effects of the above-mentioned design variables on in-plane response of SC wall piers and to 180 develop a trilinear lateral force-displacement relationship that will enable the seismic analysis of 181 structures incorporating such piers. Figure 3 is a geometrical representation of two- and three182 level full factorial design together with a face-centered central composite design of three factors $183 \mathrm{~A}, \mathrm{~B}$, and $\mathrm{C}$.

Two-level full factorial design (Figure 3a) is often used since it requires the least number 185 of simulations for a problem with many design variables [35]. However, a two-level factorial 186 design assumes that response is linear over the range of the design variables considered in the 
analysis. This assumption may not be applicable for the systems with nonlinear response [35]. In this study, a three-level, six-factor, fractional factorial design was used to build different combinations of the design variables: built using a face-centered central composite design (Figure 3b) augmented by face-centered axial and center points (shown in Figure 3b) to a twolevel six-factor full factorial design. The central composite design, which consists of a two-level full factorial design with $2^{\psi}$ runs, where $\psi$ is the number of factors, $2 \psi$ axial runs, and $n_{c}$ center runs, is used to build second-order response surface models avoiding the need to run a three-level full factorial experiment (Figure 3c). The central composite design method efficiently considers the effects of the first- (e.g., $x_{1}, x_{2}, \ldots . ., \mathrm{x}_{n}$ ) and second-order terms (e.g., $x_{1}^{2}, x_{2}^{2}, \ldots . ., \mathrm{x}_{n}^{2}$ ) on the response.

Three levels (i.e., low-, intermediate-, and high-levels) are considered for each design variable. The levels of the design parameters used in the numerical analysis are presented in Table 3. The values in parentheses show the coded values used in the analysis; the low, intermediate, and high levels of the factors are denoted by $-1,0$, and +1 , respectively.

\subsection{Analysis results}

Key analysis results are summarized in Table 4. The levels of the design variables for each run are listed in columns 2 to 7 . Columns 8 to 10 present the shear force resisted by the infill concrete and the steel faceplates, and the pre-yield stiffness of the SC walls at the onset of the steel faceplate yielding. Columns 11 to 13 list the contributions of the infill concrete and the steel faceplates to the total lateral load capacity and the post-yield stiffness of the SC walls. The pre-yield stiffness is the secant stiffness established at the force corresponding to the onset of the yielding of the steel faceplates. The post-yield stiffness is the slope of a line segment passing through the yield and reference points, where the reference point is established at the peak shear 
210 force and at a displacement calculated using an equal-energy-based tri-linear idealization of the

211 LS-DYNA-predicted force-displacement relationship.

212 The shear force, $V_{\text {flex }}$, listed in column 14 of Table 4 , is the shear force associated with the 213 plastic moment capacity of the cross-section calculated using the code XTRACT [36]. The 214 calculations assumed perfect bond between the steel faceplates and the infill concrete, steel and 215 concrete material properties per Tables 1 and 2 and Figure 1, and ignore the co-existing axial 216 force and shear force interaction, both of which affect plastic moment capacity. Column 15

217 presents the ratio of $\left(V_{c}^{p}+V_{s}^{p}\right)$ to $V_{\text {flex }}$. Values greater than 1.0 identify the shortcomings of the 218 traditional assumptions used to compute moment capacity, including plane sections remaining 219 plane after loading, and ignoring shear and axial force interaction.

220 5.2. Analysis of variance

221 An Analysis of Variance (ANOVA) was conducted using the commercial software 222 Minitab [37] to investigate the main and interaction effects of the design variables on response. 223 The results of ANOVA are presented in the following sub-sections.

\section{$224 \quad$ 5.2.1. Main effects}

225 The average values of the response variables at the low and high levels of the design 226 variables are presented in Figure 4. The plots identify the factors that have a significant effect on 227 the response of SC walls: as the slope of the line increases, the main effect of the design 228 variables increases [35]. Figure 4 shows that the aspect ratio (AR) has a significant effect on the 229 yield and peak shear load and on the pre- and post-yield lateral stiffness. The negative slope in 230 these panels delineates that as the aspect ratio increases, the lateral strength and stiffness of SC 231 walls decrease. 
233 stiffness because the slope of the RR line in the plots for $V_{y}$ and $V_{p}$ is greater than in those for

$234 K_{y}$ and $K_{p}$, whereas the slenderness ratio (SR) has no effect on $V_{y}$ and only a small effect on

$235 V_{p}$ and $K_{y}$, the post-yield stiffness is markedly influenced by slenderness ratio. As the faceplate

236 slenderness ratio increases, the post-yield stiffness decreases, which is an expected result because

237 as the slenderness ratio increases, buckling of the steel faceplates and the onset of loss of

238 stiffness occur earlier.

239 Figure 4 also shows that the axial load ratio (AL), concrete compressive strength (CS),

240 and steel yield strength (SS) have approximately the same effect on the yield and lateral load

241 capacities of SC walls. However, an increase in the axial load and concrete compressive strength

242 increase the pre- and post-yield stiffness but they decrease as the steel yield strength increases.

\section{$243 \quad$ 5.2.2. Interaction effects}

The interaction plots of the design variables are presented in Figure 5. There is significant

245 interaction between two variables if the effect of one variable on the response substantially 246 changes for different values of another variable. Parallel lines in an interaction plot indicate that

247 there is no interaction between the design variables. As the difference in the slopes of the lines 248 increases, the degree of the interaction between the design variables increases [35].

249 In Figure 5, the cells in the first row of plots in each panel present the degree of 250 interaction between aspect ratio and the other design variables. The greater the difference in the 251 slopes of the two lines in each cell, the greater the interaction. For example, in the first row in 252 panels a) and $b$ ), the lines are parallel in only one cell ( $A R+S R$ : second cell from the left), 
253 indicating that significant interaction of AR with RR, AL, SS and CS, but not with SR, in the 254 calculation of $V_{y}$ and $V_{p}$.

Figure $5 \mathrm{~b}$ and Figure $5 \mathrm{~d}$ indicate that there is an interaction between reinforcement ratio 256 and slenderness ratio, which influences the estimation of $V_{p}$ and $K_{p}$. This interaction is 257 attributed to the fact that any change in the reinforcement ratio, for a constant wall thickness, 258 changes the steel faceplate thickness and the slenderness ratio. There is also interaction between 259 axial load and concrete compressive strength because the applied compressive load is a fraction $260(0,0.1,0.2)$ of the product of the concrete compressive strength and the cross-sectional area of 261 the wall $\left(A_{g} f_{c}^{\prime}\right)$. The axial load interacts with the yield strength of the steel faceplates in the 262 calculation of $K_{p}$. An increase in the steel strength slightly increases $K_{p}$ when there is no axial

263 load but it significantly decreases $K_{p}$ at an axial load of $0.2 A_{g} f_{c}^{\prime}$ (see Figure $5 \mathrm{~d}$ ).

\section{5.3. Empirical predictive equations for the monotonic response of $S C$ wall piers}

The pre-peak-strength response of SC wall piers can be approximated by a tri-linear 266 force-displacement relationship, as presented in Figure 6. Two stages of pre-peak response are 267 assumed, namely, 1) pre-yielding and 2) post-yielding of the steel faceplates.

270 follows:

$$
\begin{aligned}
& V_{y}=\alpha_{c}^{y} A_{c} f_{c}^{\prime}+\alpha_{s}^{y} A_{s} f_{y} \\
& V_{p}=\alpha_{c}^{p} A_{c} f_{c}^{\prime}+\alpha_{s}^{p} A_{s} f_{y}
\end{aligned}
$$

The pre- and post-yield stiffness of an SC wall pier, in the absence of foundation 272 flexibility, can be calculated as: 


$$
\begin{aligned}
& K_{y}=\beta_{y} K_{e l} \\
& K_{p}=\beta_{p} K_{e l}
\end{aligned}
$$

273 where $K_{e l}$ can be calculated as:

$$
K_{e l}=K_{e l}^{c}+K_{e l}^{s}=\frac{1}{\frac{1}{K_{f c}}+\frac{1}{K_{v c}}}+\frac{1}{\frac{1}{K_{f s}}+\frac{1}{K_{v s}}}
$$

The flexural and shear stiffness are calculated as:

$$
\begin{gathered}
K_{f c}=\frac{3 E_{c} I_{c}}{H^{3}}, K_{f s}=\frac{3 E_{s} I_{s}}{H^{3}} \\
K_{v c}=\frac{G_{c} A_{c}^{e f f}}{H}, K_{v s}=\frac{G_{s} A_{s}^{e f f}}{H}
\end{gathered}
$$

The results of the finite element analyses were used to develop empirical equations to 276 calculate the strength and stiffness factors $\alpha_{c}^{y}, \alpha_{s}^{y}, \alpha_{c}^{p}, \alpha_{s}^{p}, \beta_{y}$, and $\beta_{p}$. The factors $\alpha_{c}^{y}$

277 and $\alpha_{s}^{y}$ were calculated as the LS-DYNA-predicted shear forces resisted by the infill concrete 278 and steel faceplates, respectively, at the onset of the steel faceplate yielding divided by the 279 corresponding product of their compressive (yield) strengths and area. The factors $\alpha_{c}^{p}$ and $\alpha_{s}^{p}$ 280 were calculated as the ratio of the contributions of the infill concrete and the steel faceplates to 281 the lateral load capacity of SC wall, respectively, to the corresponding product of their 282 compressive (yield) strengths and area. The factor $\beta_{y}$ was calculated as the LS-DYNA-predicted 283 normalized secant stiffness (i.e., secant stiffness divided by the theoretical initial stiffness) 284 established at the force corresponding to the onset of the yielding of the steel faceplates. Factor $285 \beta_{p}$ was estimated as the slope of the line segment passing through the yield and reference points 286 on the LS-DYNA-predicted force-displacement relationship. 
The calculated strength and stiffness factors were subsequently used as an input for the

288

289

290

291

292

293

294

295

296

297

298

299

300

301

302

303

304

305

306

307

308

ANOVA. The results of the ANOVA for $\alpha_{c}^{p}$ and $\alpha_{s}^{p}$ are presented in Table 5 including the sum of squares, percentage contribution, mean squares, F- and P-values for each item of the full quadratic terms including linear, square, and 2-way interaction terms.

The results of ANOVA for the other response factors $\alpha_{c}^{y}, \alpha_{s}^{y}, \beta_{y}$, and $\beta_{p}$ are presented in Epackachi and Whittaker [9] and are not repeated here. The total sum of squares (SS) has N-1 degrees of freedom (DF), where $\mathrm{N}$ is the number of the analyses $(=77)$. Considering full quadratic terms in the model, there are 27 terms with one degree of freedom for each term, where the degree of freedom for the main effect terms is the number of levels of the factor minus 1 and the degree of freedom of the interaction terms is calculated as the product of the degrees of freedom of the corresponding main effects. The percentage contribution, estimated as the ratio of the sum of squares for each term to the total sum of squares, shows the relative importance of each term used to predict the response variable. The mean squares calculated by dividing the sum of squares of each term to its corresponding degrees of freedom represents an estimate of the population variance. The F- and $\mathrm{P}$-values in Table 5 represent the significance of each term on the response variable. The effects of the factors with a probability less than $5 \%$ (P-value less than 0.05) are considered to be significant on the response variable at the $95 \%$ confidence level. The results presented in Table 5 help to identify the terms with significant contributions (i.e., with a P-value less than 0.05) that need to be included in the regression model.

Table 6 lists the coefficients of the linear, square, and interaction terms of the regression equations for the response factors $\alpha_{c}^{y}, \alpha_{s}^{y}, \alpha_{c}^{p}, \alpha_{s}^{p}, \beta_{y}$, and $\beta_{p}$. The coefficient of each term estimates the change in the mean response per unit increase in that term when all other 

between the coded and actual terms is:

$$
y_{c}=2\left(\frac{y_{a}-A}{B-A}\right)-1
$$

313 where $y_{c}$ and $y_{a}$ are the coded and actual values of the variable, respectively, and $A$ and $B$ are

314 the actual lower and upper limits on the variable, respectively.

\subsection{Adequacy of the regression models}

In an analysis of variance, the regression model is developed assuming that the errors are normally and independently distributed with a mean of zero. The validity of this assumption and the model adequacy can be investigated by examining the residuals, where the residual is defined as the difference between the measured and model-predicted value of the response variable. The regression model is adequate if the residuals are structureless and normally distributed [35].

The normal probability of the residuals and the LS-DYNA-predicted response variables versus residuals are presented in Figure 7. The residuals of the response variables, presented in the left panels of Figure 7, are linear, indicating that the distribution of the residuals is normal. The plots of residuals versus response variables presented in the right panels of Figure 7 investigate the independence assumption in the analysis of variance. As seen in Figure 7, the plots of the residuals versus the response variables are random and structureless, indicating that the assumption of independence is valid.

\section{Mechanics-based Equations for Predicting Peak Flexural Strength}

Experimental and numerical investigations on the in-plane seismic response of SC wall piers $[10,12,38]$ have made it clear that behavior is governed by flexure unless the aspect ratio 
331 is much less than 0.5. Flexural (and thus shear) capacity is limited by buckling of the steel

332 faceplates at the free vertical edges of the wall. The significant interaction of shear and axial

333 forces, and bending moment, on lateral load capacity of SC wall piers shown above makes it

334 clear that strength-based predictive equations ignoring coupled behavior may be substantially

335 inaccurate and lead to unconservative designs. Herein, the interactions between shear and axial

336 force, and bending moment, are considered in the derivation of equations for in-plane flexural

337 capacity of SC walls that could be implemented in a design standard. The lateral capacity of an

338 SC walls can be calculated by dividing its flexural capacity by its moment-to-shear ratio (or the

339 height a single story wall panel).

The derivation of mechanics-based equations for composite systems, which address the

341 interaction of key design variables, utilizes insight gained from finite element analysis of

342 validated models. A parametric study was conducted considering aspect ratios ranging from 0.3

343 to 3.0 , reinforcement ratios ranging from $1.6 \%$ to $6.6 \%$, and axial load ratio ranging from 0 to

$3440.2 \mathrm{~m}$, where these terms were described previously. ASTM A36 steel was assumed for the steel

345 faceplates, with values of the yield and tensile strengths of 262 and $380 \mathrm{MPa}$, respectively. The

346 compressive strength of the infill concrete was assumed to be $27.5 \mathrm{MPa}$. The length and

347 thickness of the wall models were the same as the 77 models used for derivation of the ANOVA-

348 based equations. The material models, element types, boundary conditions, and loading were the

349 same as those discussed previously.

$350 \quad$ 6.1. Analysis results

351 Figure 8 presents the variation of the averaged normal stress in the steel faceplates and in

352 the infill concrete at peak lateral resistance for the $\mathrm{SC}$ walls with aspect ratios ranging from 0.3

353 to 3 . As seen in Figure 8, the vertical stress profiles in the steel faceplates and infill concrete are

354 significantly affected by shear-flexure interaction for walls with aspect ratios of less than 1.5. As 
355 aspect ratio decreases, the shear stress increases and the extent of yielding on the tension side of 356 the steel faceplates decreases. Figure 8 shows that the neutral axis for the steel faceplates and the 357 infill concrete are not collocated for walls with an aspect ratio of less than 1.5, noting that the 358 distance between the neutral axes decreases as the aspect ratio increases. Figure 8 also indicates 359 that the maximum tensile and compressive strain at the wall ends increase as the aspect ratio 360 increases and the extent of yielding on the compression side of the steel faceplates increases. As 361 seen in Figure 8, the tensile stress in the infill concrete decreases as the aspect ratio increases. The effect of axial load on the vertical stress profiles in the steel faceplates and the infill 363 concrete is presented in Figure 9. As the axial compressive force increases, the depths to the 364 neutral axes in the steel faceplates and the infill concrete from the extreme fibers in compression 365 both increase., which is an expected result.

Figure 10 presents the effect of reinforcement ratio on the vertical stress profiles in the 367 steel faceplates and infill concrete. The slope of the stress profile on the tension side of the steel 368 faceplates decreases as the reinforcement ratio increases. The depth to the neutral axis in the steel 369 faceplates also increases as the reinforcement ratio increases.

The finite element analysis results were used to aid the derivation of a mechanics-based

371 predictive equation for the flexural capacity of SC wall piers. Figure 11 presents the strain and 372 stress profiles in the steel faceplates and infill concrete used in the derivation

373 The vertical stress distributions predicted by LS-DYNA in the infill concrete and steel 374 faceplates at the base of the SC walls with different aspect ratios, reinforcement ratios, and axial 375 load ratios were used to propose expressions for modification factors $\lambda_{1}, \lambda_{2}$, and $\lambda_{3}$. The effect 376 of moment-to-shear ratio on the maximum strain in the extreme fiber in compression, $\varepsilon_{c}$, is 377 given by $\lambda_{1}$ : 
$\lambda_{1}=\frac{M / V L-0.3}{1.2}$

378 where $M / V L$ is the normalized moment-to-shear ratio, noting that the normalized moment-to-

379 shear ratio is identical to the wall aspect ratio, $H / L$, for a single story wall panel. The 380 numerical analysis results indicated that the neutral axis in the steel faceplates and infill concrete 381 are not collocated for low-aspect ratio SC walls. The difference between the neutral axis depths 382 of the infill concrete and steel faceplates, $c^{\prime}$ and $c$ in Figure 11 respectively, is given by 383 parameter $\lambda_{2}$ :

$\lambda_{2}=1.42(M / V L)^{-0.86}$

384 The difference between $c^{\prime}$ and $c$ decreases as $M / V L$ increases and they are effectively identical 385 for $M / V L \geq 1.5$.

As seen in Figure 8 and Figure 9, the vertical stress and strain do not distribute linearly 387 along the length of the wall due to shear-flexure interaction, and the assumption of plane sections 388 remaining plane after bending is violated. On the basis of the results of the finite element analyses, the strain variation for low aspect ratio SC wall piers can be represented by the bi-

390 linear relationship shown in Figure 11b. The slope of the strain profile on the tension side is a 391 function of aspect ratio, axial load ratio, and reinforcement ratio. The effect of these parameters 392 on the slope of the stress profile is considered by parameter $\lambda_{3}$ :

$$
\lambda_{3}=\left(1+\frac{N}{0.2 f_{c}^{\prime} A_{g}}\left(1.21(M / V L)^{-0.48}-1\right)\right)(0.05 \exp (2 M / V L))\left(0.17 \rho_{s}+0.75\right) \leq 1.0
$$

393 The strain profile is linear for SC walls with an aspect ratio of 1.5 and greater.

The parameter $\varepsilon_{c}$ is varied from the yield strain of the steel faceplates to the ultimate strain of the infill concrete $(=0.004)$ as the aspect ratio increases from 0.3 to 1.5 , and it remains 396 constant for aspect ratios greater than 1.5: 


$$
\varepsilon_{c}=\varepsilon_{y}\left(1-\lambda_{1}\right)+\varepsilon_{c u} \lambda_{1}
$$

398 parameters $\lambda_{1}, \lambda_{2}$, and $\lambda_{3}$ from Equations (9) to (11) and $\varepsilon_{c}$ from Equation (12), the depth to the 399 neutral axis can be calculated as:

$$
c=\frac{\frac{N}{A_{s} f_{y}}+1+\varphi^{\prime}}{\lambda_{2}\left(\varphi+\varphi^{\prime}\right)+k\left(1-\lambda_{3}\right) /\left(2 \lambda_{3}\right)+2}
$$

400 where

$$
\begin{aligned}
& \varphi=\frac{\beta_{1} \beta_{2} f_{c}^{\prime}}{\rho_{s} f_{s}^{*}} \\
& \varphi^{\prime}=\frac{f_{t}^{*}}{\rho_{s} f_{s}^{*}} \\
& k=\frac{\varepsilon_{y}}{\varepsilon_{c}}
\end{aligned}
$$

401 Given the value of $c$ and setting $\alpha=c / L, \lambda_{3 \min }$ is:

$$
\lambda_{3 \min }=\frac{\varepsilon_{y} \alpha}{(1-\alpha) \varepsilon_{c}}
$$

402 If $\lambda_{3}<\lambda_{3 \min }, c$ needs to be re-calculated assuming $\lambda_{3}=\lambda_{3 \min }$.

403 The values of the stress block parameters, $\beta_{1}$ and $\beta_{2}$ in Equation (14), are calculated 404 assuming that the equivalent rectangular stress block recovers the area under the concrete stress405 strain relationship and the location of its resultant, respectively. Table 7 lists the values these 406 stress block parameters as a function of $\varepsilon_{c}$. The concrete stress-strain relationship proposed by 407 Tsai [39] was used to calculate the stress block parameters. The bending moment capacity of an SC wall pier can then be calculated as: 


$$
M_{u}=\beta_{1} \beta_{2} f_{c}^{\prime} A_{c} L_{c}+A_{s} f_{s}^{*} L_{s}+A_{c} f_{t}^{*} L_{c}^{\prime}
$$

409 where

$$
\begin{aligned}
& L_{c}=L\left[\lambda_{2} \alpha\left(1-\beta_{2} \lambda_{2} \alpha\right) / 2\right] \\
& L_{c}^{\prime}=L\left[\lambda_{2} \alpha\left(1-\lambda_{2} \alpha\right) / 2\right] \\
& \left.L_{s}=\alpha L\left[1+0.25 k\left(1 / \lambda_{3}-1\right)-\alpha\left(1+0.5 k\left(1 / \lambda_{3}-1\right)+k^{2}\left(1 / \lambda_{3}^{2}+1\right) / 6\right)\right)\right]
\end{aligned}
$$

Numerical analyses indicated that as the aspect ratio increases, the vertical strain in the

411 steel faceplates and infill concrete increases, leading to an increase in the vertical stress in the 412 faceplates due to hardening and to a reduction in the tensile stress in the infill concrete due to 413 cracking. On the basis of the finite element analysis results, the effective stress in the steel

414 faceplates, $f_{s}^{*}$, and the effective tensile strength of the infill concrete, $f_{t}^{*}$, can be calculated as:

$$
\begin{aligned}
& 1.05 f_{y} \leq f_{s}^{*}=[1.05+0.056(M / V L-0.3)] f_{y} \leq 1.2 f_{y} \\
& 0 \leq f_{t}^{*}=0.185(3-M / V L) f \leq 0.5 f_{t}
\end{aligned}
$$

Given the bending moment capacity, the lateral load capacity of SC walls can be 416 calculated as:

$$
V_{u}=\frac{M_{u}}{H^{*}}
$$

Figure 13 presents a flowchart for the calculation of the moment capacity of an SC wall 418 pier.

\subsection{Verification of the proposed equations}

Figure 12 presents the DYNA-predicted normal stress profiles in the steel faceplates and

421 infill concrete at peak lateral load together with those predicted using the equations (9) to (17).

422 As seen in Figure 12, the proposed equations accurately predict the normal stress variation in the 423 steel faceplates and infill concrete of SC walls with different moment-to-shear, reinforcement, and axial load ratios. The locations of the neutral axes and change in the slope of the normal 
425 stress profile on the tension and compression sides of the steel faceplates predicted by the 426 proposed equations match the DYNA-predicted results.

The DYNA- and mechanics-based-predicted lateral load capacities of the SC walls with

428 different aspect ratio, reinforcement ratio, and axial load ratio are listed in Table 8. The

429 mechanics-based-predicted lateral load capacities, listed in Table 8, were calculated using

430 Equation (24). The lateral load capacities of the SC walls are predicted with an error of less than

$43115 \%$. The lateral load capacity is significantly underestimated if the tensile strength of the infill

432 concrete is ignored.

433

434

435

436

437

438

\section{Verification and validation of the mechanics-based and ANOVA-based equations}

Two sets of data are used to verify and validate the proposed mechanics-based and ANOVA-based equations for peak resistance of an SC wall pier: LS-DYNA analysis and data from tests of four SC walls with an aspect ratio of 0.5 .

\subsection{Verification}

The results of analysis of the 77 LS-DYNA models presented in Table 4 are used to validate the ANOVA-based and mechanics-based equations. Figure 14 presents three normalized lateral load capacities for each of 77 models. The normalized lateral load capacities were estimated by dividing the lateral load capacity calculated based on (1) ANOVA-based Equation (2), (2) mechanics-based Equation (24), and (3) specifications of AISC 341-17 [40], to the DYNA-predicted peak load. The draft Standard AISC 341-17 [40], includes provisions for design of composite plate shear walls: concrete filled (C-PSW/CF). Section H7.5a of AISC 34117 specifies that the nominal moment capacity of C-PSW/CF without boundary elements be calculated as the moment corresponding to yielding of the steel faceplates in flexural tension and 
447 first yield in flexural compression assuming a linear elastic stress distribution, a maximum

448 concrete compressive stress equal to $0.7 f_{c}^{\prime}$, and maximum steel stress equal to $f_{y}$.

The ratio of lateral load capacity predicted by the ANOVA-based Equation (2) and the mechanics-based Equation (18) to the DYNA-predicted peak load varies from 0.82 to 1.2 , indicating that both equations reasonably recover the numerically predicted lateral load capacity. We consider this outcome to verify the mechanics-based design equation.

There are significant differences between the AISC- and numerically-predicted lateral load capacities because the proposed AISC equations ignore the effects of wall aspect ratio, reinforcement ratio, and axial load.

\subsection{Validation}

Data from the in-plane testing of SC walls by Chen [38, 41] are used for further independent validation of the accuracy of the mechanics-based and ANOVA-based models. Data from the tests at the University at Buffalo were not utilized for this purpose because they were used to validate the LS-DYNA model.

Chen $[38,41]$ tested four low-aspect ratio SC walls under displacement-controlled cyclic loading. The aspect ratio of the four walls was 0.5 . The height and the length of the walls were $1220 \mathrm{~mm}$ and $2000 \mathrm{~mm}$, respectively. The distance between the wall base and the center line of the loading plates was $1000 \mathrm{~mm}$. The steel faceplates were embedded into the foundation block using shear studs attached to the inside of the steel plates. Holes in the steel faceplates enabled the placement of transverse reinforcement in the foundation block. The total wall thickness was $290 \mathrm{~mm}$ for SC1 and SC2 and $200 \mathrm{~mm}$ for SC3 and SC4. The faceplates were 4.5-mm thick, yielding reinforcement ratios of $3.1 \%$ and $4.5 \%$ for $\mathrm{SC} 1 / \mathrm{SC} 2$ and $\mathrm{SC} 3 / \mathrm{SC} 4$, respectively. The diameter of the studs and tie rods was $13 \mathrm{~mm}$. Studs and tie rods were used in SC1 and SC3 but 
470 only tie rods were used in SC2 and SC4. The studs were spaced $75 \mathrm{~mm}$ on center in SC1 and

471 SC3. Tie rods were spaced at $150 \mathrm{~mm}$ in all SC walls. A photograph of SC1 is presented in

472 Figure 15. More information about the material properties, test setup, loading protocol, and 473 instrumentation are reported in Chen [38, 41].

$474 \quad$ Figure 16 presents the measured first-quadrant cyclic force-displacement relationships 475 (solid gray line) for the walls tested by Chen, the mechanics-based lateral strengths per Equation 476 (24) (dashed black line), ANOVA-based prediction of monotonic response per Equations (1) to 477 (7) (dotted blue line), and the LS-DYNA-predicted monotonic response (solid red line). The LS478 DYNA analyses of Chen's walls were performed using the same material models, elements, and 479 boundary conditions used for the analysis of $77 \mathrm{SC}$ wall piers described previously.

480 The predictive equations, proposed in this study for response under monotonic loading, 481 slightly overestimate the cyclic response of Chen's walls [41], which is an expected outcome. 482 Figure 16 shows that the ANOVA-based predictions of monotonic response and the mechanics483 based predictions of peak strength agree well with the monotonic responses predicted by analysis 484 of the LS-DYNA models.

\section{Summary and Conclusions}

The effects of key design variables on the in-plane response of SC wall piers without

487 boundary elements were studied systematically and results were used to develop predictive 488 equations for the monotonic lateral force- displacement relationship up to peak strength, and a 489 mechanics-based equation for the lateral load capacity, of SC wall piers. The general-purpose 490 finite element code LS-DYNA was used for the simulations. The baseline model was validated 491 in a prior study by the authors for calculations of in-plane, inelastic cyclic response, using data 492 from tests of large-size wall piers. 
The design variables considered in this study included wall aspect ratio ranging from 0.3

494 to 3.0 , reinforcement ratio ranging from $1.6 \%$ to $6.6 \%$, slenderness ratio ranging from 10 to 50 ,

495 axial load ratio ranging from 0 to 0.2 , steel strength ranging from 235 to $460 \mathrm{MPa}$, and concrete

496 strength ranging from 27 to $55 \mathrm{MPa}$.

497

Statistical analyses were performed to investigate the main and interaction effects of the

498 key design variables on the lateral strength and stiffness of SC walls using a three-level

499 fractional factorial design method. Lateral load capacity and stiffness are affected significantly

500 by aspect ratio. Although faceplate slenderness ratio had the smallest effect on strength and

501 initial stiffness, it has a marked effect on post-yield stiffness: the greater slenderness ratio, the

502 lower the post-yield stiffness. Aspect ratio has a substantial impact on global response; as it

503 increases, the effects of other design variables on strength and stiffness decrease.

504

The results of the LS-DYNA analyses were used to develop a tri-linear relationship for

505 the monotonic response of an SC wall pier up to peak strength. The adequacy of the proposed 506 relationship was verified by examining the independency and normal distribution of the 507 residuals.

508 A mechanics-based equation was developed for predicting the bending moment capacity 509 of an SC wall pier considering the co-existing shear and axial forces, and the effects of aspect 510 ratio, axial load, and reinforcement ratio. Importantly, this study showed that the bending511 moment capacity of SC wall piers cannot be predicted accurately by equation proposed in ASIC 512341 because the effects of key design variables and the axial force-shear force interaction are 513 ignored.

The proposed mechanics-based and ANOVA-based equations were verified and validated 515 using finite element analysis results and data from tests of four low-aspect ratio SC wall piers at 
National Taiwan University. The DYNA-predicted peak load of 77 SC walls with various design variables and the in-plane monotonic response up to peak load of the tested SC walls were successfully predicted using the proposed equations.

The proposed mechanics-based and ANOVA-based equations are applicable for the range of design variables considered in this study. Further studies are needed to expand the ranges of

521 the design variables and to address SC walls with boundary columns and flanges.

522

523

524

525

526

527

\section{Acknowledgements}

This project was supported in part by the US National Science Foundation under Grant No. CMMI-0829978. This support is gratefully acknowledged. The authors thank Mr. B. Chen and Professor Yin-Nan Huang at the National Taiwan University for providing data from their tests of SC walls that were used for the validation study presented in the paper.

\section{References}

[1] Akita S, Ozaki M, Niwa N, Matsuo I, Hara K. Study on steel plate reinforced concrete bearing wall for nuclear power plants (part \#2): analytical method to evaluate response of SC walls. 22nd International Conference on Structural Mechanics in Reactor Technology (SMiRT16). Washington DC, USA: International Association for Structural Mechanics in Reactor Technology (IASMiRT); 2001.

[2] Akiyama H, Sekimoto H, Tanaka M, Inoue K, Fukihara M, Okuda Y. 1/10th scale model test of inner concrete structure composed of concrete filled steel bearing wall. 10th International Conference on Structural Mechanics in Reactor Technology (SMiRT10). Anaheim, California, USA: International Association for Structural Mechanics in Reactor Technology (IASMiRT); 1989. p. 73-8.

[3] Bowerman H, Coyle N, Chapman JC. An innovative steel/concrete construction system. The Structural Engineer. 2002; 80:33-8.

[4] Chaudhary S, Ali A, Kim D, Cho SG. Seismic analysis of steel concrete composite walls of nuclear power plant structures. 21th International Conference on Structural Mechanics in Reactor Technology (SMiRT21). New Delhi, India: International Association for Structural Mechanics in Reactor Technology (IASMiRT); 2011. 
[5] Danay A. Response of steel-concrete composite panels to in-plane loading. Nuclear Engineering and Design. 2012;242:52-62.

[6] Emori K. Compressive and shear strength of concrete filled steel box wall. Steel Structures (Korean journal). 2002;2:29-40.

[7] Eom TS, Park HG, Lee CH, Kim JH, Chang IH. Behavior of double skin composite wall subjected to in-plane cyclic loading. Journal of Structural Engineering. 2009;135:1239-49.

[8] Epackachi S. Experimental, numerical, and analytical studies on the seismic response of steel-plate concrete (SC) composite shear walls Buffalo. Ph.D. Dissertation. Buffalo, NY: University at Buffalo; 2014.

[9] Epackachi S, Whittaker AS. Experimental, numerical, and analytical studies on the seismic response of steel-plate concrete (SC) composite shear walls. MCEER Technical Report 160001. Buffalo, NY: University at Buffalo; 2016.

[10] Epackachi S, Nguyen NH, Kurt EG, Whittaker AS, Varma AH. In-plane seismic behavior of rectangular steel-plate composite wall piers. Journal of Structural Engineering. 2014; 141: 04014176-1-9.

[11] Epackachi S, Whittaker AS, Huang YN. Analytical modeling of rectangular SC wall panels. Journal of Construction Steel Research. 2014; 105:49-59.

[12] Kurt EG, Varma AH, Booth P, Whittaker AS. In-plane behavior and design of rectangular sc wall piers without boundary elements. Journal of Structural Engineering. 2016; 142: 04016026-1-16.

[13] Nie JG, Hu HS, Fan JS, Tao MX, Li SY, Liu FJ. Experimental study on seismic behavior of high-strength concrete filled double-steel-plate composite walls. Journal of Constructional Steel Research. 2013;88:206-19.

[14] Ozaki M, Akita S, Niwa N, Matsuo I, Usami S. Study on steel plate reinforced concrete bearing wall for nuclear power plants part 1: shear and bending loading tests of SC walls. 16th International Conference on Structural Mechanics in Reactor Technology (SMiRT16). Washington DC, USA: International Association for Structural Mechanics in Reactor Technology (IASMiRT); 2001.

[15] Sener KC, Varma AH. Steel-plate composite walls: experimental database and design for out-of-plane shear. Journal of Constructional Steel Research. 2014;100:197-210.

[16] Suzuki N, Akiyama H, Narikawa M, Hara K, Takeuchi M, Matsuo I. Study on a concrete filled steel structure for nuclear power plants (part \#4): analytical method to estimate shear strength. 13th International Conference on Structural Mechanics in Reactor Technology 
(SMiRT13). Porto Alegre, Brazil: International Association for Structural Mechanics in Reactor Technology (IASMiRT); 1995. p. 33-8.

[17] Usami S, Akiyama H, Narikawa M, Hara K, Takeuchi M, Sasaki N. Study on a concrete filled steel structure for nuclear power plants (part \#2): compressive loading tests on wall members. 13th International Conference on Structural Mechanics in Reactor Technology (SMiRT13). Porto Alegre, Brazil: International Association for Structural Mechanics in Reactor Technology (IASMiRT); 1995. p. 21-6.

[18] Varma AH, Malushte SR, Sener KC, Lai Z. Steel-plate composite (SC) walls for safety related nuclear facilities: Design for in-plane forces and out-of-plane moments. Nuclear Engineering and Design. 2014;269:240-9.

[19] Vecchio F, McQuade I. Towards improved modeling of steel-concrete composite wall elements. Nuclear Engineering and Design. 2011;241:2629-42.

[20] Zhao Q, Astaneh-Asl A. Cyclic behavior of traditional and innovative composite shear walls. Journal of Structural Engineering. 2004;130:271-84.

[21] Fukumoto T, Kato B, Sato K. Concrete filled steel bearing walls. IABSE report.1987.

[22] Takeda T, Yamaguchi T, Nakayama T, Akiyama K, Kato Y. Experimental study on shear characteristics of concrete filled steel plate wall. 13th International Conference on Structural Mechanics in Reactor Technology (SMiRT13). Porto Alegre, Brazil: International Association for Structural Mechanics in Reactor Technology (IASMiRT); 1995. p. 3-14.

[23] Sasaki N, Akiyama H, Narikawa M, Hara K, Takeuchi M, Usami S. Study on a concrete filled steel structure for nuclear power plants (part \#2): shear and bending loading tests on wall member. 13th International Conference on Structural Mechanics in Reactor Technology (SMiRT13). Porto Alegre, Brazil: International Association for Structural Mechanics in Reactor Technology (IASMiRT); 1995. p. 27-32.

[24] Jian-Guo N, Hong-Song H, Jian-Sheng F, Mu-Xuan T, Sheng-Yong L, Fu-Jun L. Experimental study on seismic behavior of high-strength concrete filled double-steel-plate composite walls. Journal of Constructional Steel Research. 2013;88:206-19.

[25] SIMULIA. Abaqus Analysis User's Manual. Providence, Rhode Island, USA: Version 6.12, Dassault Systèmes Simulia Corp.; 2012.

[26] Epackachi S, Whittaker AS, Varma AH, Kurt EG. Finite element modeling of rectangular steel-plate composite shear walls. Engineering Structures. 2015; 100:369-84. 
[27] LS-DYNA. Keyword User's Manual, Volume I. Livermore, CA, USA: Version 971 R6.0.0; 2012.

[28] LS-DYNA. Keyword User's Manual, Volume II. Livermore, CA, USA: Version 971 R6.0.0; 2012.

[29] ACI 318 Committee. Building code requirements for structural concrete (ACI 318-14) and commentary. Farmington Hills, MI: American Concrete Institute; 2014.

[30] Ozcebe G. Saatcioglu M. Hysteretic shear model for reinforced concrete members. Journal of structural engineering New York, NY. 1989;115:132-48.

[31] Baltay P, Gjelsvik A. Coefficient of friction for steel on concrete at high normal stress. Journal of Materials in Civil Engineering. 1990;2:46-9.

[32] Rabbat BG, Russell HG. Friction coefficient of steel on concrete or grout. Journal of Structural Engineering. 1985;111:505-15.

[33] Han L-H, He S-H, Liao F-Y. Performance and calculations of concrete filled steel tubes (CFST) under axial tension. Journal of Constructional Steel Research. 2011;67:1699-709.

[34] Moon J, Roeder CW, Lehman DE, Lee H-E. Analytical modeling of bending of circular concrete-filled steel tubes. Engineering Structures. 2012;42:349-61.

[35] Montgomery DC. Design and analysis of experiments. 4th Ed. New York: Wiley; 1982.

[36] Chadwell CB, Imbsen RA. XTRACT-cross section analysis software for structural and earthquake engineering. Rancho Cordova, CA: TRC; 2002.

[37] Minitab. Minitab Manual. Minitab Inc.; 2013.

[38] Chang CC, Huang YN, Chen BA, Epackachi S, Whittaker A. An experimental study for inplane cyclic behavior of low aspect-ratio steel-concrete composite walls. 23rd Int Conf on Structural Mechanics in Reactor Technology (SMiRT 23). Manchester, UK: International Association for Structural Mechanics in Reactor Technology (IASMiRT); 2015.

[39] Tsai WT. Uniaxial compressional stress- strain relation of concrete. Journal of Structural Engineering. 1988;114:2133-6.

[40] American Institute of Steel Construction. Seismic provisions for structural steel buildings (AISC341). public review ballot 2. Chicago; 2017.

[41] Chen PA. An experimental study of the in-plane cyclic behavior of low-aspect-ratio steelplate composite walls. Master Thesis. Taiwan: National Taiwan University; 2015. 


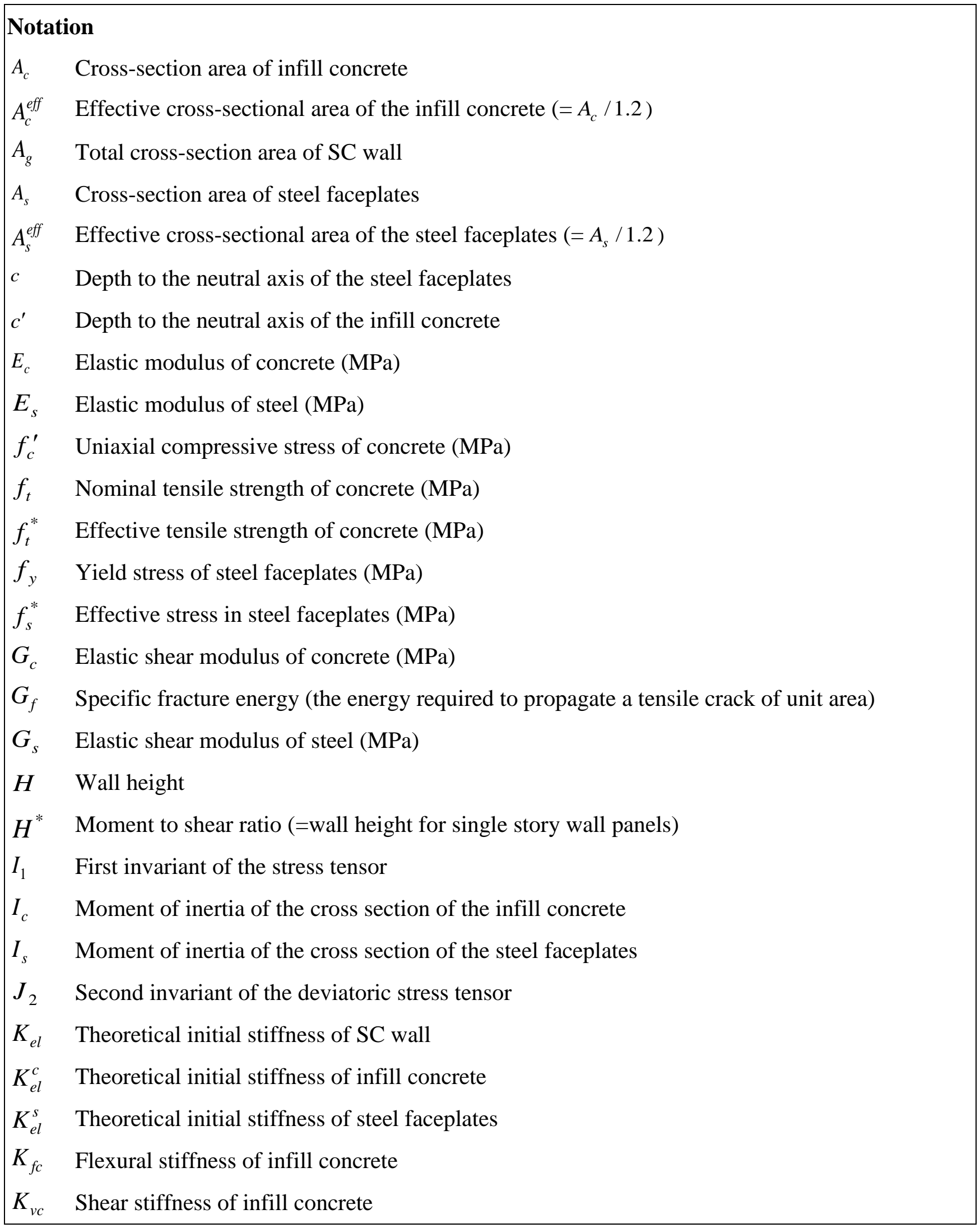




\begin{tabular}{|ll|}
\hline$K_{f s}$ & Flexural stiffness of steel faceplates \\
$K_{v s}$ & Shear stiffness of steel faceplates \\
$K_{e l}^{s}$ & Theoretical initial stiffness of steel faceplates \\
$K_{y}$ & Pre-yield stiffness of SC wall \\
$K_{P}$ & Post-yield stiffness of SC wall \\
$L$ & Length of wall \\
$M$ & Bending moment \\
$N$ & Axial load \\
$V_{c}^{y}$ & Shear force resisted by infill concrete at the onset of steel faceplate yielding \\
$V_{s}^{y}$ & Shear force resisted by steel faceplates at the onset of steel faceplate yielding \\
$V_{y}$ & Lateral force resisted by SC wall at the onset of steel faceplate yielding \\
$V_{c}^{p}$ & Shear force resisted by infill concrete at peak lateral load \\
$V_{s}^{p}$ & Shear force resisted by steel faceplates at peak lateral load \\
$V_{p}$ & Lateral load capacity of SC wall \\
$V_{f l e x}^{*}$ & Shear force associated with the ultimate moment capacity of SC wall cross-section \\
$t_{c}$ & Thickness of infill concrete \\
$t_{s}$ & Thickness of each steel faceplate \\
$w$ & Crack width \\
$\theta$ & Lodge angle varying between 0 and $\pi / 3$ \\
$\varepsilon_{c}$ & Concrete strain at extreme fiber in compression \\
$\varepsilon_{c u}$ & Ultimate concrete strain \\
$\varepsilon_{y}$ & Steel strain at yielding \\
$\rho_{s}$ & Reinforcement ratio \\
$\beta_{1}$ & Stress block coefficient \\
$\beta_{2}$ & Stress block coefficient \\
\hline & \\
\hline
\end{tabular}




\section{$530 \quad$ List of Figures}

531 Figure 1. Stress-strain relationships for the steel material

532 Figure 2. LS-DYNA model

533 Figure 3. Three factor factorial design

534 Figure 4. Main effect plots of design variables

535 Figure 5. Interaction plots of design variables

536 Figure 6. Tri-linear shear force-displacement relationship

537 Figure 7. Plots of normal probability versus residual (left) and residual versus LS-DYNA-

538 predicted response variable (right)

539 Figure 8. DYNA-predicted normal stress in steel faceplates and infill concrete at peak lateral

540 load for zero axial load, $f_{c}^{\prime}=27.5 \mathrm{MPa}_{2} f_{y}=260 \mathrm{MPa}$

541 Figure 9. DYNA-predicted normal stress in steel faceplates and infill concrete at peak strength

542 for an axial load ratio of $0.2, f_{c}^{\prime}=27.5 \mathrm{MPa}_{2} f_{y}=260 \mathrm{MPa}$

543 Figure 10. Effect of reinforcement ratio on the steel and concrete normal stress profiles at the

544 wall base

545 Figure 11. Moment capacity calculation; (a) SC wall cross section; (b) vertical strain profile; (c)

546 vertical stress profile in infill concrete; and (d) vertical stress profile in steel faceplates

547 Figure 12. LS-DYNA and model predicted responses

548 Figure 13. Lateral load capacity calculation for SC wall piers

549 Figure 14. Predicted normalized lateral load capacity of the SC walls

550 Figure 15. SC1 specimen before the test [10]

551 Figure 16. Predicted and measured responses of the SC walls 


\section{$553 \quad$ List of Tables}

554 Table 1. Concrete material properties

555 Table 2. Steel material properties

556 Table 3. Levels of the design parameters

557 Table 4. LS-DYNA and cross-sectional analysis results

558 Table 5. Results of ANOVA for $\alpha_{c}^{p}$ and $\alpha_{s}^{p}$

559 Table 6. Coefficients of the regression models for the response variables

560 Table 7. Values of the stress block parameters

561 Table 8. Predicted lateral load capacities

562

563 
Table 1. Concrete material properties

\begin{tabular}{c|c|c|c|c|c|c}
\hline $\begin{array}{c}\text { Compressive } \\
\text { strength level }\end{array}$ & $\begin{array}{c}\text { Young's } \\
\text { modulus } \\
(\mathrm{MPa})\end{array}$ & $\begin{array}{c}\text { Poisson's } \\
\text { ratio }\end{array}$ & $\begin{array}{c}\text { Uniaxial } \\
\text { compressive } \\
\text { strength } \\
(\mathrm{MPa})\end{array}$ & $\begin{array}{c}\text { Uniaxial } \\
\text { tensile } \\
\text { strength } \\
(\mathrm{MPa})\end{array}$ & $\begin{array}{c}\text { Crack } \\
\text { width } \\
(\mathrm{mm})\end{array}$ & $\begin{array}{c}\text { Agg. } \\
\text { size } \\
(\mathrm{mm})\end{array}$ \\
\hline Low & 24856 & 0.20 & 27.6 & 2.8 & 0.052 & 19 \\
Intermediate & 30442 & 0.20 & 41.4 & 3.6 & 0.052 & 19 \\
High & 35151 & 0.20 & 55.2 & 4.4 & 0.053 & 19 \\
\hline
\end{tabular}

571

572 
Table 2. Steel material properties

576

577

578

579

580

\begin{tabular}{c|c|c|c|c|c}
\hline Yield strength level & $\begin{array}{c}\text { Young's } \\
\text { modulus } \\
(\mathrm{MPa})\end{array}$ & $\begin{array}{c}\text { Poisson's } \\
\text { ratio }\end{array}$ & $\begin{array}{c}\text { Yield } \\
\text { strength } \\
(\mathrm{MPa})\end{array}$ & $\begin{array}{c}\text { Ultimate } \\
\text { strength } \\
(\mathrm{MPa})\end{array}$ & $\begin{array}{c}\text { Fracture } \\
\text { strain } \\
(\%)\end{array}$ \\
\hline Low & 200000 & 0.30 & 235 & 390 & 24 \\
Intermediate & 200000 & 0.30 & 350 & 460 & 22 \\
High & 200000 & 0.30 & 460 & 635 & 19 \\
\hline
\end{tabular}

581

582 
Table 3. Levels of the design parameters

\begin{tabular}{l|c|c|c}
\hline \multicolumn{1}{c|}{ Variable } & Low & Intermediate & High \\
\hline Aspect ratio & $0.5(-1)$ & $1.25(0)$ & $2.0(+1)$ \\
Reinforcement ratio (\%) & $1.67(-1)$ & $3.33(0)$ & $5.0(+1)$ \\
Slenderness ratio & $10(-1)$ & $25(0)$ & $40(+1)$ \\
Axial load ratio & $0(-1)$ & $0.1(0)$ & $0.2(+1)$ \\
Yield strength of the steel faceplates (MPa) & $235(-1)$ & $350(0)$ & $460(+1)$ \\
Concrete compressive strength (MPa) & $27.6(-1)$ & $41.4(0)$ & $55.2(+1)$ \\
\hline
\end{tabular}

583

584 
Table 4. LS-DYNA and cross-sectional analysis results

\begin{tabular}{|c|c|c|c|c|c|c|c|c|c|c|c|c|c|c|}
\hline \multirow{3}{*}{ Run } & \multicolumn{6}{|c|}{ Factor levels } & \multicolumn{3}{|c|}{ Data at yield point } & \multicolumn{3}{|c|}{ Data at peak point } & \multicolumn{2}{|c|}{$\begin{array}{c}\text { Cross-sectional } \\
\text { analysis }\end{array}$} \\
\hline & AR & RR & SR & AL & SS & CS & $V_{c}^{y}$ & $V_{s}^{y}$ & $K_{y}$ & $V_{c}^{p}$ & $V_{s}^{p}$ & $K_{p}$ & $V_{f l e x}$ & $\frac{V_{c}^{p}+V_{s}^{p}}{U}$ \\
\hline & & & & & & & $(\mathrm{kN})$ & $(\mathrm{kN})$ & $(\mathrm{kN} / \mathrm{mm})$ & $(\mathrm{kN})$ & $(\mathrm{kN})$ & $(\mathrm{kN} / \mathrm{mm})$ & $(\mathrm{kN})$ & $V_{f l e x}$ \\
\hline (1) & (2) & (3) & $(4)$ & $(5)$ & (6) & (7) & (8) & $(9)$ & (10) & (11) & (12) & (13) & (14) & (15) \\
\hline 1 & -1 & -1 & -1 & -1 & -1 & -1 & 965 & 227 & 3069 & 1646 & 641 & 1357 & 1601 & 1.43 \\
\hline 2 & -1 & -1 & -1 & -1 & -1 & 1 & 1419 & 240 & 4260 & 2224 & 627 & 1833 & 1686 & 1.69 \\
\hline 3 & -1 & -1 & -1 & -1 & 1 & -1 & 1552 & 645 & 1909 & 1917 & 1388 & 1576 & 2865 & 1.15 \\
\hline 4 & -1 & -1 & -1 & -1 & 1 & 1 & 2126 & 592 & 2656 & 2985 & 1277 & 1916 & 3145 & 1.36 \\
\hline 5 & -1 & -1 & -1 & 1 & -1 & -1 & 1962 & 369 & 3629 & 2535 & 801 & 2109 & 3132 & 1.06 \\
\hline 6 & -1 & -1 & -1 & 1 & -1 & 1 & 3154 & 360 & 5471 & 4639 & 827 & 3106 & 5004 & 1.09 \\
\hline 7 & -1 & -1 & -1 & 1 & 1 & -1 & 2371 & 725 & 2691 & 2553 & 1615 & 1944 & 3954 & 1.05 \\
\hline 8 & -1 & -1 & -1 & 1 & 1 & 1 & 4035 & 636 & 4563 & 4488 & 1592 & 3131 & 5921 & 1.03 \\
\hline 9 & -1 & -1 & 1 & -1 & -1 & -1 & 1085 & 271 & 2626 & 1610 & 605 & 976 & 1601 & 1.38 \\
\hline 10 & -1 & -1 & 1 & -1 & -1 & 1 & 1610 & 271 & 3652 & 2180 & 480 & 670 & 1579 & 1.69 \\
\hline 11 & -1 & -1 & 1 & -1 & 1 & -1 & 1312 & 480 & 1999 & 1873 & 1339 & 936 & 2865 & 1.12 \\
\hline 12 & -1 & -1 & 1 & -1 & 1 & 1 & 1939 & 480 & 2698 & 2829 & 1157 & 1321 & 3145 & 1.27 \\
\hline 13 & -1 & -1 & 1 & 1 & -1 & -1 & 2117 & 405 & 3283 & 2402 & 765 & 1429 & 3132 & 1.01 \\
\hline 14 & -1 & -1 & 1 & 1 & -1 & 1 & 3527 & 396 & 5100 & 4395 & 778 & 1656 & 5004 & 1.03 \\
\hline 15 & -1 & -1 & 1 & 1 & 1 & -1 & 2406 & 707 & 2438 & 2264 & 1570 & 950 & 3954 & 0.97 \\
\hline 16 & -1 & -1 & 1 & 1 & 1 & 1 & 4288 & 698 & 3906 & 4399 & 1294 & 1664 & 5921 & 0.96 \\
\hline 17 & -1 & 1 & -1 & -1 & -1 & -1 & 1201 & 823 & 3921 & 2202 & 2024 & 2303 & 4110 & 1.03 \\
\hline 18 & -1 & 1 & -1 & -1 & -1 & 1 & 1739 & 832 & 4989 & 3501 & 1886 & 2324 & 4537 & 1.19 \\
\hline 19 & -1 & 1 & -1 & -1 & 1 & -1 & 1726 & 1619 & 3270 & 2718 & 4502 & 1889 & 6970 & 1.04 \\
\hline 20 & -1 & 1 & -1 & -1 & 1 & 1 & 2277 & 1450 & 4158 & 4097 & 4137 & 2620 & 7740 & 1.06 \\
\hline 21 & -1 & 1 & -1 & 1 & -1 & -1 & 2042 & 1237 & 4261 & 2527 & 2304 & 3103 & 5120 & 0.94 \\
\hline 22 & -1 & 1 & -1 & 1 & -1 & 1 & 3403 & 1219 & 6003 & 4537 & 2286 & 3664 & 7055 & 0.97 \\
\hline 23 & -1 & 1 & -1 & 1 & 1 & -1 & 2313 & 1913 & 3675 & 2776 & 4706 & 2146 & 7504 & 1.00 \\
\hline 24 & -1 & 1 & -1 & 1 & 1 & 1 & 4168 & 2131 & 4931 & 4510 & 4791 & 2587 & 9186 & 1.01 \\
\hline 25 & -1 & 1 & 1 & -1 & -1 & -1 & 1348 & 961 & 3596 & 2189 & 2037 & 2114 & 4110 & 1.03 \\
\hline 26 & -1 & 1 & 1 & -1 & -1 & 1 & 1953 & 952 & 4521 & 3296 & 1922 & 2238 & 4537 & 1.15 \\
\hline 27 & -1 & 1 & 1 & -1 & 1 & -1 & 1704 & 1552 & 3181 & 2540 & 4417 & 1950 & 6970 & 1.00 \\
\hline 28 & -1 & 1 & 1 & -1 & 1 & 1 & 2429 & 1539 & 3875 & 3981 & 3848 & 2781 & 7740 & 1.01 \\
\hline 29 & -1 & 1 & 1 & 1 & -1 & -1 & 2068 & 1174 & 4215 & 2473 & 2273 & 2603 & 5120 & 0.93 \\
\hline 30 & -1 & 1 & 1 & 1 & -1 & 1 & 3421 & 1165 & 5958 & 4622 & 2295 & 3569 & 7055 & 0.98 \\
\hline 31 & -1 & 1 & 1 & 1 & 1 & -1 & 2442 & 1988 & 3467 & 2527 & 4582 & 1891 & 7504 & 0.95 \\
\hline 32 & -1 & 1 & 1 & 1 & 1 & 1 & 4221 & 1979 & 4856 & 4253 & 4599 & 2842 & 9186 & 0.96 \\
\hline
\end{tabular}


Table 4. LS-DYNA and cross-sectional analysis results (cont.)

\begin{tabular}{|c|c|c|c|c|c|c|c|c|c|c|c|c|c|c|}
\hline \multirow{2}{*}{ Run } & \multicolumn{6}{|c|}{ Factor levels } & \multicolumn{3}{|c|}{ Data at yield point } & \multicolumn{3}{|c|}{ Data at peak point } & \multicolumn{2}{|c|}{$\begin{array}{c}\text { Cross-sectional } \\
\text { analysis }\end{array}$} \\
\hline & $\begin{array}{l}\text { AR } \\
\text { (2) }\end{array}$ & $\begin{array}{l}\text { RR } \\
\text { (3) }\end{array}$ & $\begin{array}{l}\text { SR } \\
\text { (4) }\end{array}$ & $\begin{array}{l}\mathrm{AL} \\
(5)\end{array}$ & $\begin{array}{l}\text { SS } \\
\text { (6) }\end{array}$ & $\begin{array}{l}\text { CS } \\
\text { (7) }\end{array}$ & $\begin{array}{c}V_{c}^{y} \\
(\mathrm{kN}) \\
(8)\end{array}$ & $\begin{array}{c}V_{s}^{y} \\
(\mathrm{kN}) \\
(9)\end{array}$ & $\begin{array}{c}K_{y} \\
(\mathrm{kN} / \mathrm{mm}) \\
(10)\end{array}$ & $\begin{array}{c}V_{c}^{p} \\
(\mathrm{kN}) \\
(11)\end{array}$ & $\begin{array}{l}V_{s}^{p} \\
(\mathrm{kN}) \\
(12)\end{array}$ & $\begin{array}{c}K_{p} \\
(\mathrm{kN} / \mathrm{mm}) \\
(13)\end{array}$ & $\begin{array}{l}V_{\text {flex }} \\
(\mathrm{kN}) \\
(14)\end{array}$ & $\frac{V_{c}^{p}+V_{s}^{p}}{V_{\text {flex }}}$ \\
\hline 33 & 1 & -1 & -1 & -1 & -1 & -1 & 240 & 67 & 151 & 307 & 200 & 43 & 400 & 1.27 \\
\hline 34 & 1 & -1 & -1 & -1 & -1 & 1 & 329 & 67 & 221 & 387 & 178 & 42 & 396 & 1.43 \\
\hline 35 & 1 & -1 & -1 & -1 & 1 & -1 & 249 & 182 & 95 & 556 & 409 & 57 & 716 & 1.35 \\
\hline 36 & 1 & -1 & -1 & -1 & 1 & 1 & 298 & 209 & 142 & 716 & 329 & 60 & 787 & 1.33 \\
\hline 37 & 1 & -1 & -1 & 1 & -1 & -1 & 507 & 111 & 194 & 663 & 249 & 81 & 783 & 1.17 \\
\hline 38 & 1 & -1 & -1 & 1 & -1 & 1 & 983 & 102 & 271 & 1286 & 245 & 103 & 1250 & 1.22 \\
\hline 39 & 1 & -1 & -1 & 1 & 1 & -1 & 445 & 187 & 107 & 863 & 463 & 66 & 988 & 1.34 \\
\hline 40 & 1 & -1 & -1 & 1 & 1 & 1 & 1134 & 187 & 223 & 1419 & 480 & 85 & 1481 & 1.28 \\
\hline 41 & 1 & -1 & 1 & -1 & -1 & -1 & 236 & 93 & 120 & 276 & 236 & 34 & 400 & 1.28 \\
\hline 42 & 1 & -1 & 1 & -1 & -1 & 1 & 351 & 98 & 163 & 414 & 191 & 25 & 396 & 1.53 \\
\hline 43 & 1 & -1 & 1 & -1 & 1 & -1 & 173 & 222 & 85 & 463 & 431 & 47 & 716 & 1.25 \\
\hline 44 & 1 & -1 & 1 & -1 & 1 & 1 & 236 & 254 & 109 & 587 & 409 & 46 & 787 & 1.27 \\
\hline 45 & 1 & -1 & 1 & 1 & -1 & -1 & 547 & 129 & 169 & 689 & 240 & 60 & 783 & 1.19 \\
\hline 46 & 1 & -1 & 1 & 1 & -1 & 1 & 983 & 138 & 248 & 1272 & 236 & 76 & 1250 & 1.21 \\
\hline 47 & 1 & -1 & 1 & 1 & 1 & -1 & 556 & 240 & 132 & 672 & 547 & 51 & 988 & 1.23 \\
\hline 48 & 1 & -1 & 1 & 1 & 1 & 1 & 1045 & 249 & 198 & 1286 & 520 & 84 & 1481 & 1.22 \\
\hline 49 & 1 & 1 & -1 & -1 & -1 & -1 & 316 & 254 & 190 & 592 & 658 & 92 & 1028 & 1.22 \\
\hline 50 & 1 & 1 & -1 & -1 & -1 & 1 & 431 & 254 & 239 & 814 & 596 & 86 & 1134 & 1.24 \\
\hline 51 & 1 & 1 & -1 & -1 & 1 & -1 & 436 & 494 & 160 & 867 & 1375 & 94 & 1744 & 1.29 \\
\hline 52 & 1 & 1 & -1 & -1 & 1 & 1 & 520 & 489 & 192 & 1268 & 1299 & 108 & 1935 & 1.33 \\
\hline 53 & 1 & 1 & -1 & 1 & -1 & -1 & 543 & 334 & 226 & 765 & 747 & 111 & 1281 & 1.18 \\
\hline 54 & 1 & 1 & -1 & 1 & -1 & 1 & 939 & 360 & 305 & 1446 & 694 & 132 & 1761 & 1.21 \\
\hline 55 & 1 & 1 & -1 & 1 & 1 & -1 & 636 & 609 & 191 & 930 & 1481 & 91 & 1877 & 1.28 \\
\hline 56 & 1 & 1 & -1 & 1 & 1 & 1 & 1076 & 641 & 257 & 1650 & 1428 & 119 & 2295 & 1.34 \\
\hline 57 & 1 & 1 & 1 & -1 & -1 & -1 & 245 & 289 & 164 & 423 & 752 & 77 & 1028 & 1.14 \\
\hline 58 & 1 & 1 & 1 & -1 & -1 & 1 & 320 & 329 & 199 & 520 & 770 & 93 & 1134 & 1.14 \\
\hline 59 & 1 & 1 & 1 & -1 & 1 & -1 & 262 & 578 & 139 & 556 & 1601 & 90 & 1744 & 1.24 \\
\hline 60 & 1 & 1 & 1 & -1 & 1 & 1 & 258 & 658 & 158 & 787 & 1624 & 100 & 1935 & 1.25 \\
\hline 61 & 1 & 1 & 1 & 1 & -1 & -1 & 480 & 396 & 206 & 636 & 823 & 108 & 1281 & 1.14 \\
\hline 62 & 1 & 1 & 1 & 1 & -1 & 1 & 903 & 431 & 280 & 1259 & 787 & 117 & 1761 & 1.16 \\
\hline 63 & 1 & 1 & 1 & 1 & 1 & -1 & 476 & 738 & 169 & 543 & 1793 & 89 & 1877 & 1.24 \\
\hline 64 & 1 & 1 & 1 & 1 & 1 & 1 & 961 & 770 & 229 & 1143 & 1810 & 104 & 2295 & 1.29 \\
\hline
\end{tabular}


Table 4. LS-DYNA and cross-sectional analysis results (cont.)

\begin{tabular}{|c|c|c|c|c|c|c|c|c|c|c|c|c|c|c|}
\hline \multirow[b]{2}{*}{ Run } & \multicolumn{6}{|c|}{ Factor levels } & \multicolumn{3}{|c|}{ Data at yield point } & \multicolumn{3}{|c|}{ Data at peak point } & \multicolumn{2}{|c|}{$\begin{array}{c}\text { Cross-sectional } \\
\text { analysis }\end{array}$} \\
\hline & $\mathrm{AR}$ & $\begin{array}{l}\text { RR } \\
\text { (3) }\end{array}$ & SR & $\begin{array}{l}\mathrm{AL} \\
(5)\end{array}$ & SS & CS & $\begin{array}{c}V_{c}^{y} \\
(\mathrm{kN}) \\
(8)\end{array}$ & $\begin{array}{c}V_{s}^{y} \\
(\mathrm{kN}) \\
(9)\end{array}$ & $\begin{array}{c}K_{y} \\
(\mathrm{kN} / \mathrm{mm}) \\
(10)\end{array}$ & $\begin{array}{l}V_{c}^{p} \\
(\mathrm{kN})\end{array}$ & $\begin{array}{l}V_{s}^{p} \\
(\mathrm{kN})\end{array}$ & $\begin{array}{c}K_{p} \\
(\mathrm{kN} / \mathrm{mm})\end{array}$ & $\begin{array}{l}V_{\text {flex }} \\
(\mathrm{kN})\end{array}$ & $\frac{V_{c}^{p}+V_{s}^{p}}{V_{\text {flex }}}$ \\
\hline 65 & 0 & 0 & 0 & 0 & 0 & 0 & 992 & 476 & 624 & 1446 & 1157 & 273 & 1984 & 1.31 \\
\hline 66 & -1 & 0 & 0 & 0 & 0 & 0 & 2491 & 1005 & 3652 & 3345 & 2064 & 2406 & 4964 & 1.09 \\
\hline 67 & 1 & 0 & 0 & 0 & 0 & 0 & 311 & 289 & 149 & 743 & 556 & 72 & 1241 & 1.05 \\
\hline 68 & 0 & -1 & 0 & 0 & 0 & 0 & 1014 & 236 & 561 & 1254 & 556 & 154 & 1415 & 1.28 \\
\hline 69 & 0 & 1 & 0 & 0 & 0 & 0 & 992 & 756 & 670 & 1775 & 1584 & 249 & 2722 & 1.23 \\
\hline 70 & 0 & 0 & -1 & 0 & 0 & 0 & 1005 & 489 & 634 & 1597 & 1108 & 248 & 1984 & 1.36 \\
\hline 71 & 0 & 0 & 1 & 0 & 0 & 0 & 996 & 512 & 577 & 1517 & 1032 & 193 & 1984 & 1.29 \\
\hline 72 & 0 & 0 & 0 & -1 & 0 & 0 & 636 & 423 & 504 & 1197 & 970 & 160 & 1659 & 1.30 \\
\hline 73 & 0 & 0 & 0 & 1 & 0 & 0 & 1352 & 547 & 695 & 1842 & 1165 & 292 & 2402 & 1.25 \\
\hline 74 & 0 & 0 & 0 & 0 & -1 & 0 & 947 & 356 & 706 & 1312 & 796 & 270 & 1575 & 1.34 \\
\hline 75 & 0 & 0 & 0 & 0 & 1 & 0 & 1054 & 632 & 564 & 1637 & 1668 & 227 & 2398 & 1.38 \\
\hline 76 & 0 & 0 & 0 & 0 & 0 & -1 & 743 & 476 & 518 & 1112 & 1139 & 240 & 1721 & 1.31 \\
\hline 77 & 0 & 0 & 0 & 0 & 0 & 1 & 1241 & 507 & 705 & 1939 & 1032 & 219 & 2224 & 1.34 \\
\hline
\end{tabular}


Table 5. Results of ANOVA for $\alpha_{c}^{p}$ and $\alpha_{s}^{p}$

\begin{tabular}{|c|c|c|c|c|c|c|c|c|c|c|c|c|}
\hline & \multirow{2}{*}{ Var. } & \multirow{2}{*}{ DF } & \multicolumn{5}{|c|}{ Response factor $\alpha_{c}^{p}$} & \multicolumn{5}{|c|}{ Response factor $\alpha_{s}^{p}$} \\
\hline & & & Seq SS & Contr. & MS & F-Val. & P-Val. & Seq SS & Contr. & MS & F-Val. & P-Val. \\
\hline \multirow{6}{*}{ 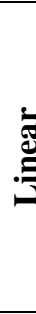 } & AR & 1 & 0.2403 & $82.46 \%$ & 0.2403 & 5082.8 & 0.00 & 1.1472 & $91.37 \%$ & 1.1472 & 5947.8 & 0.00 \\
\hline & $\mathrm{RR}$ & 1 & 0.0051 & $1.75 \%$ & 0.0051 & 107.6 & 0.00 & 0.0037 & $0.29 \%$ & 0.0037 & 19.1 & 0.00 \\
\hline & SR & 1 & 0.0013 & $0.43 \%$ & 0.0013 & 26.7 & 0.00 & 0.0001 & $0.01 \%$ & 0.0001 & 0.6 & 0.43 \\
\hline & $\mathrm{AL}$ & 1 & 0.0169 & $5.80 \%$ & 0.0169 & 357.2 & 0.00 & 0.0323 & $2.58 \%$ & 0.0323 & 167.7 & 0.00 \\
\hline & SS & 1 & 0.0020 & $0.70 \%$ & 0.0020 & 43.0 & 0.00 & 0.0026 & $0.21 \%$ & 0.0026 & 13.4 & 0.00 \\
\hline & $\mathrm{CS}$ & 1 & 0.0061 & $2.08 \%$ & 0.0061 & 128.1 & 0.00 & 0.0033 & $0.26 \%$ & 0.0033 & 17.0 & 0.00 \\
\hline \multirow{6}{*}{ 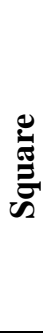 } & $\mathrm{AR}^{2}$ & 1 & 0.0059 & $2.01 \%$ & 0.0017 & 35.7 & 0.00 & 0.0302 & $2.41 \%$ & 0.0042 & 21.5 & 0.00 \\
\hline & $\mathrm{RR}^{2}$ & 1 & 0.0000 & $0.00 \%$ & 0.0000 & 0.1 & 0.82 & 0.0002 & $0.02 \%$ & 0.0000 & 0.0 & 0.99 \\
\hline & $\mathrm{SR}^{2}$ & 1 & 0.0000 & $0.00 \%$ & 0.0000 & 0.1 & 0.79 & 0.0001 & $0.00 \%$ & 0.0000 & 0.1 & 0.79 \\
\hline & $\mathrm{AL}^{2}$ & 1 & 0.0000 & $0.00 \%$ & 0.0000 & 0.0 & 0.86 & 0.0000 & $0.00 \%$ & 0.0000 & 0.2 & 0.70 \\
\hline & $\mathrm{SS}^{2}$ & 1 & 0.0000 & $0.01 \%$ & 0.0000 & 0.5 & 0.50 & 0.0015 & $0.12 \%$ & 0.0015 & 7.7 & 0.01 \\
\hline & $\mathrm{CS}^{2}$ & 1 & 0.0000 & $0.00 \%$ & 0.0000 & 0.1 & 0.74 & 0.0000 & $0.00 \%$ & 0.0000 & 0.0 & 1.00 \\
\hline \multirow{18}{*}{ 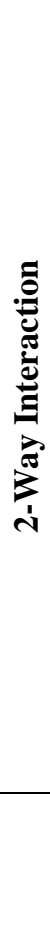 } & $\mathrm{AR} \times \mathrm{RR}$ & 1 & 0.0015 & $0.50 \%$ & 0.0015 & 30.7 & 0.00 & 000 & $0.00 \%$ & .0000 & 0.0 & 0.91 \\
\hline & $\mathrm{AR} \times \mathrm{SR}$ & 1 & 0.0000 & $0.01 \%$ & 0.0000 & 0.8 & 0.37 & 0.0061 & $0.49 \%$ & 0.0061 & 31.6 & 0.00 \\
\hline & $\mathrm{AR} \times \mathrm{AL}$ & 1 & 0.0018 & $0.63 \%$ & 0.0018 & 38.9 & 0.00 & 0.0096 & $0.76 \%$ & 0.0096 & 49.7 & 0.00 \\
\hline & $\mathrm{AR} \times \mathrm{SS}$ & 1 & 0.0001 & $0.02 \%$ & 0.0001 & 1.4 & 0.24 & 0.0005 & $0.04 \%$ & 0.0005 & 2.4 & 0.13 \\
\hline & $\mathrm{AR} \times \mathrm{CS}$ & 1 & 0.0020 & $0.69 \%$ & 0.0020 & 42.6 & 0.00 & 0.0009 & $0.07 \%$ & 0.0009 & 4.4 & 0.04 \\
\hline & $\mathrm{RR} \times \mathrm{SR}$ & 1 & 0.0002 & $0.06 \%$ & 0.0002 & 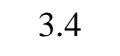 & 0.07 & 0.0019 & $0.15 \%$ & 0.0019 & 9.6 & 0.00 \\
\hline & $\mathrm{RR} \times \mathrm{AL}$ & 1 & 0.0032 & $1.09 \%$ & 0.0032 & 67.0 & 0.00 & 0.0026 & $0.20 \%$ & 0.0026 & 13.3 & 0.00 \\
\hline & $\mathrm{RR} \times \mathrm{SS}$ & 1 & 0.0000 & $0.01 \%$ & 0.0000 & 0.5 & 0.47 & 0.0004 & $0.03 \%$ & 0.0004 & 1.9 & 0.18 \\
\hline & $\mathrm{RR} \times \mathrm{CS}$ & 1 & 0.0001 & $0.03 \%$ & 0.0001 & 1.6 & 0.21 & 0.0003 & $0.02 \%$ & 0.0003 & 1.4 & 0.24 \\
\hline & $\mathrm{SR} \times \mathrm{AL}$ & 1 & 0.0000 & $0.01 \%$ & 0.0000 & 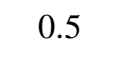 & 0.47 & 0.0000 & $0.00 \%$ & 0.0000 & 0.1 & 0.77 \\
\hline & $\mathrm{SR} \times \mathrm{SS}$ & 1 & 0.0003 & $0.10 \%$ & 0.0003 & 5.9 & 0.02 & 0.0000 & $0.00 \%$ & 0.0000 & 0.0 & 0.88 \\
\hline & $\mathrm{SR} \times \mathrm{CS}$ & 1 & 0.0001 & $0.03 \%$ & 0.0001 & 1.7 & 0.21 & 0.0003 & $0.03 \%$ & 0.0003 & 1.7 & 0.20 \\
\hline & $\mathrm{AL} \times \mathrm{SS}$ & 1 & 0.0015 & $0.50 \%$ & 0.0015 & 30.9 & 0.00 & 0.0008 & $0.07 \%$ & 0.0008 & 4.3 & 0.04 \\
\hline & $\mathrm{AL} \times \mathrm{CS}$ & 1 & 0.0008 & $0.28 \%$ & 0.0008 & 17.3 & 0.00 & 0.0013 & $0.11 \%$ & 0.0013 & 6.9 & 0.01 \\
\hline & $\mathrm{SS} \times \mathrm{CS}$ & 1 & 0.0001 & $0.02 \%$ & 0.0001 & 1.5 & 0.23 & 0.0002 & $0.02 \%$ & 0.0002 & 1.2 & 0.28 \\
\hline & Model & 27 & 27 & 0.2891 & $99.21 \%$ & 0.2891 & 226.5 & 27 & 1.2461 & $99.25 \%$ & 0.0462 & 239.3 \\
\hline & Error & 49 & 49 & 0.0023 & $0.79 \%$ & & & 49 & 0.0095 & $0.75 \%$ & & \\
\hline & Total & 76 & 76 & 0.2914 & $100.00 \%$ & & & 76 & 1.2555 & $100.00 \%$ & & \\
\hline
\end{tabular}


Table 6. Coefficients of the regression models for the response variables

\begin{tabular}{c|c|c|c|c|c|c|c|c|c|c|c}
\hline \multicolumn{2}{c|}{$\alpha_{s}^{y}$} & \multicolumn{2}{c|}{$\alpha_{c}^{y}$} & \multicolumn{2}{c|}{$\alpha_{s}^{p}$} & \multicolumn{2}{c|}{$\alpha_{c}^{p}$} & \multicolumn{2}{|c|}{$\beta_{y}$} & \multicolumn{2}{c}{$\beta_{p}$} \\
\hline Term & Coeff. & Term & Coeff. & Term & Coeff. & Term & Coeff. & Term & Coeff. & Term & Coeff. \\
\hline Cons. & 0.0914 & Cons. & 0.0522 & Cons. & 0.2018 & Cons. & 0.0790 & Cons. & 0.5909 & Cons. & 0.2215 \\
AR & -0.0591 & $\mathrm{AR}$ & -0.0487 & $\mathrm{AR}$ & -0.1318 & $\mathrm{AR}$ & -0.0603 & $\mathrm{AR}$ & 0.0099 & $\mathrm{AR}$ & -0.0291 \\
$\mathrm{RR}$ & 0.0014 & $\mathrm{RR}$ & 0.0027 & $\mathrm{RR}$ & 0.0075 & $\mathrm{RR}$ & 0.0088 & $\mathrm{RR}$ & 0.0189 & $\mathrm{RR}$ & 0.0414 \\
$\mathrm{SR}$ & 0.0038 & $\mathrm{SR}$ & 0.0002 & $\mathrm{SR}$ & -0.0014 & $\mathrm{SR}$ & -0.0044 & $\mathrm{SR}$ & -0.0295 & $\mathrm{SR}$ & -0.0299 \\
$\mathrm{AL}$ & 0.0164 & $\mathrm{AL}$ & 0.0229 & $\mathrm{AL}$ & 0.0221 & $\mathrm{AL}$ & 0.0160 & $\mathrm{AL}$ & 0.0780 & $\mathrm{AL}$ & 0.0431 \\
$\mathrm{SS}$ & -0.0033 & $\mathrm{SS}$ & 0.0071 & $\mathrm{SS}$ & 0.0063 & $\mathrm{SS}$ & 0.0055 & $\mathrm{SS}$ & -0.0752 & $\mathrm{SS}$ & -0.0073 \\
$\mathrm{AR}$ & 0.0262 & $\mathrm{CS}$ & -0.0081 & $\mathrm{CS}$ & -0.0071 & $\mathrm{CS}$ & -0.0096 & $\mathrm{CS}$ & 0.0137 & $\mathrm{CS}$ & -0.0113 \\
$\mathrm{AR} \times \mathrm{SR}$ & 0.0026 & $\mathrm{AR}$ & 0.0248 & $\mathrm{AR}$ & 0.0391 & $\mathrm{AR}$ & 0.0249 & $\mathrm{AR}$ & 0.0037 & $\mathrm{AR}$ & 0.0705 \\
$\mathrm{AR} \times \mathrm{AL}$ & -0.0100 & $\mathrm{AR} \times \mathrm{RR}$ & -0.0017 & $\mathrm{SS}$ & 0.0223 & $\mathrm{AR} \times \mathrm{RR}$ & -0.0048 & $\mathrm{AR} \times \mathrm{SR}$ & -0.0096 & $\mathrm{AR} \times \mathrm{SR}$ & 0.0117 \\
$\mathrm{AR} \times \mathrm{SS}$ & 0.0038 & $\mathrm{AR} \times \mathrm{SR}$ & -0.0020 & $\mathrm{AR} \times \mathrm{SR}$ & 0.0098 & $\mathrm{AR} \times \mathrm{AL}$ & -0.0054 & $\mathrm{AR} \times \mathrm{AL}$ & 0.0113 & $\mathrm{AR} \times \mathrm{SS}$ & 0.0077 \\
$\mathrm{RR} \times \mathrm{SS}$ & -0.0042 & $\mathrm{AR} \times \mathrm{AL}$ & -0.0116 & $\mathrm{AR} \times \mathrm{AL}$ & -0.0122 & $\mathrm{AR} \times \mathrm{CS}$ & 0.0056 & $\mathrm{RR} \times \mathrm{AL}$ & -0.0140 & $\mathrm{RR} \times \mathrm{SR}$ & 0.0214 \\
$\mathrm{SR} \times \mathrm{SS}$ & -0.0028 & $\mathrm{AR} \times \mathrm{SS}$ & -0.0066 & $\mathrm{AR} \times \mathrm{CS}$ & 0.0037 & $\mathrm{RR} \times \mathrm{AL}$ & -0.0070 & $\mathrm{RR} \times \mathrm{SS}$ & 0.0195 & $\mathrm{RR} \times \mathrm{AL}$ & -0.0124 \\
$\mathrm{AL} \times \mathrm{SS}$ & -0.0046 & $\mathrm{AR} \times \mathrm{CS}$ & 0.0058 & $\mathrm{RR} \times \mathrm{SR}$ & 0.0054 & $\mathrm{SR} \times \mathrm{SS}$ & -0.0021 & $\mathrm{RR} \times \mathrm{CS}$ & -0.0119 & $\mathrm{RR} \times \mathrm{SS}$ & -0.0107 \\
& & $\mathrm{RR} \times \mathrm{AL}$ & -0.0026 & $\mathrm{RR} \times \mathrm{AL}$ & -0.0063 & $\mathrm{AL} \times \mathrm{SS}$ & -0.0048 & $\mathrm{SR} \times \mathrm{SS}$ & 0.0095 & $\mathrm{SR} \times \mathrm{AL}$ & -0.0075 \\
& & $\mathrm{SR} \times \mathrm{SS}$ & -0.0015 & $\mathrm{AL} \times \mathrm{SS}$ & -0.0036 & $\mathrm{AL} \times \mathrm{CS}$ & 0.0036 & $\mathrm{AL} \times \mathrm{CS}$ & 0.0187 & $\mathrm{AL} \times \mathrm{SS}$ & -0.0230 \\
& & $\mathrm{AL} \times \mathrm{CS}$ & 0.0014 & $\mathrm{AL} \times \mathrm{CS}$ & 0.0046 & & & & & $\mathrm{AL} \times \mathrm{CS}$ & 0.0098 \\
& & & & & & & & & $\mathrm{SS} \times \mathrm{CS}$ & 0.0097 \\
\hline
\end{tabular}


Table 7. Values of the stress block parameters

\begin{tabular}{c|c|c}
\hline$\varepsilon_{c}$ & $\beta_{1}$ & $\beta_{2}$ \\
\hline 0.001 & 0.55 & 0.70 \\
0.0015 & 0.75 & 0.72 \\
0.002 & 0.88 & 0.75 \\
0.0025 & 0.94 & 0.78 \\
0.003 & 0.96 & 0.81 \\
0.0035 & 0.97 & 0.83 \\
0.004 & 0.98 & 0.85 \\
\hline
\end{tabular}

593

594 
Table 8. Predicted lateral load capacities

\begin{tabular}{|c|c|c|c|c|c|}
\hline \multirow{2}{*}{ AR } & \multirow{2}{*}{$\mathrm{AL}$} & \multirow{2}{*}{$\mathrm{RR}(\%)$} & \multicolumn{2}{|c|}{$\begin{array}{l}\text { Predicted lateral load capacity } \\
\qquad[\mathrm{kN}]\end{array}$} & \multirow{2}{*}{ Ratio } \\
\hline & & & LS-DYNA & $\begin{array}{c}\text { Mechanics-based } \\
\text { equation ( } 27)\end{array}$ & \\
\hline 0.3 & 0 & 1.6 & 2954 & 3083 & 0.96 \\
\hline 0.3 & 0.2 & 1.6 & 4070 & 4662 & 0.87 \\
\hline 0.5 & 0 & 1.6 & 2282 & 2037 & 1.12 \\
\hline 0.5 & 0 & 3.3 & 3474 & 3172 & 1.10 \\
\hline 0.5 & 0 & 5 & 4404 & 4168 & 1.06 \\
\hline 0.5 & 0 & 6.6 & 4404 & 5093 & 0.86 \\
\hline 0.5 & 0.2 & 1.6 & 3358 & 3207 & 1.05 \\
\hline 1 & 0 & 1.6 & 1117 & 1094 & 1.02 \\
\hline 1 & 0 & 3.3 & 1953 & 1886 & 1.04 \\
\hline 1 & 0 & 5 & 2736 & 2535 & 1.08 \\
\hline 1 & 0 & 6.6 & 3479 & 3145 & 1.11 \\
\hline 1 & 0.2 & 1.6 & 1882 & 1766 & 1.07 \\
\hline 1.5 & 0 & 1.6 & 725 & 747 & 0.97 \\
\hline 1.5 & 0 & 3.3 & 1228 & 1210 & 1.01 \\
\hline 1.5 & 0 & 5 & 1677 & 1632 & 1.03 \\
\hline 1.5 & 0 & 6.6 & 2117 & 2024 & 1.05 \\
\hline 1.5 & 0.2 & 1.6 & 1237 & 1205 & 1.03 \\
\hline 2 & 0 & 1.6 & 512 & 569 & 0.90 \\
\hline 2 & 0.2 & 1.6 & 912 & 912 & 1.00 \\
\hline 3 & 0 & 1.6 & 320 & 356 & 0.90 \\
\hline 3 & 0.2 & 1.6 & 574 & 618 & 0.93 \\
\hline
\end{tabular}

595

596

597

598 


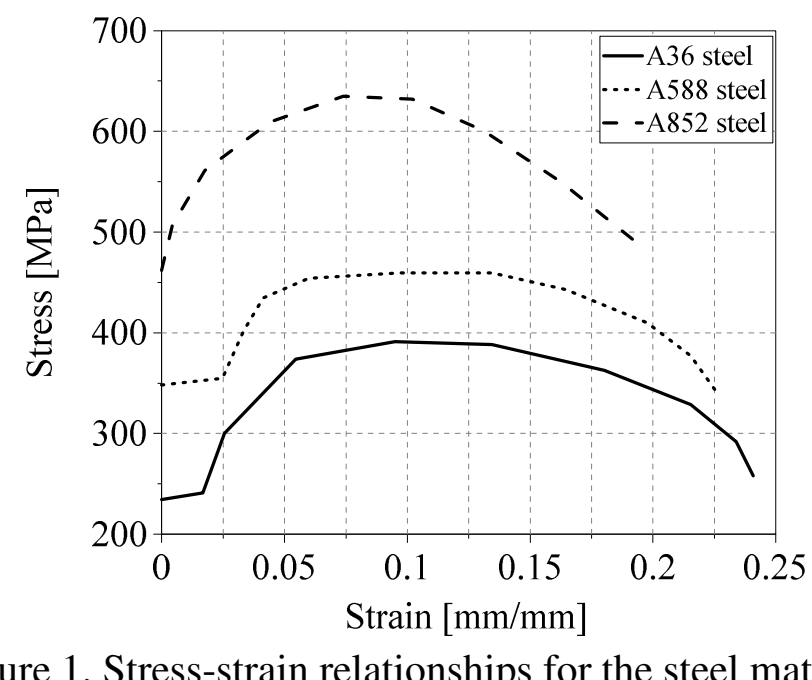

Figure 1. Stress-strain relationships for the steel material 


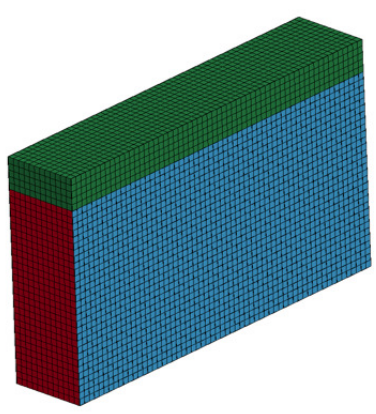

Infill concrete

Connectors attached to faceplates

(b) aspect ratio of 1.0

(a) aspect ratio of 0.5

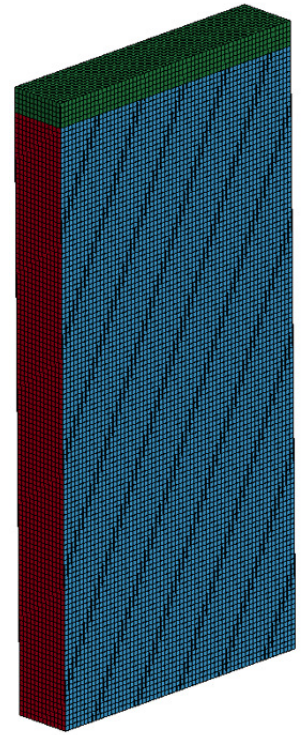

(c) aspect ratio of 2.0

Figure 2. LS-DYNA model 


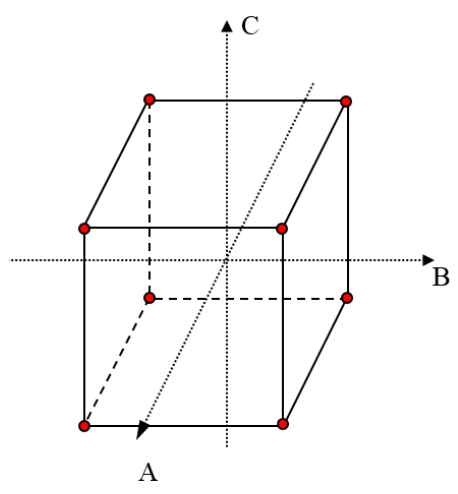

(a) Two level full factorial design

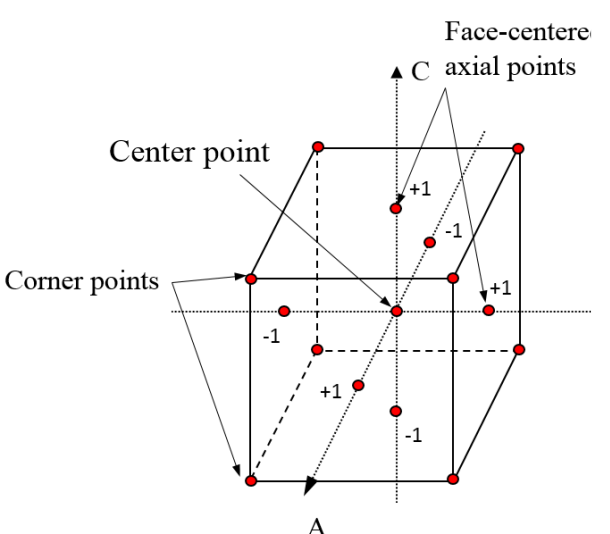

(b) Three level face-centered central composite design

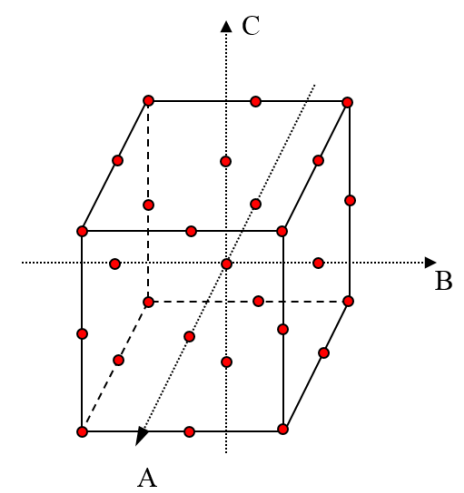

(c) Three level full factorial design

Figure 3. Three factor factorial design 


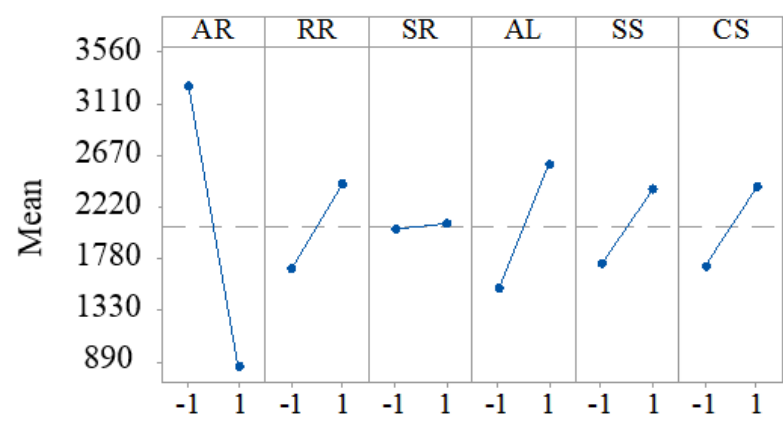

(a) $V_{y}(\mathrm{kN})$

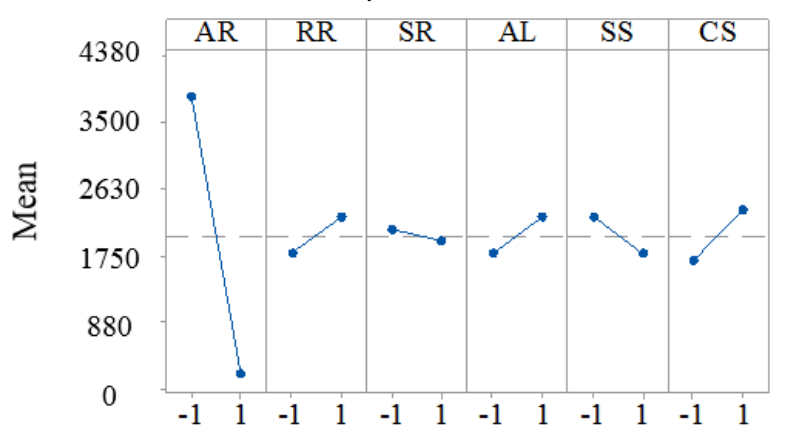

(c) $K_{y}(\mathrm{kN} / \mathrm{mm})$

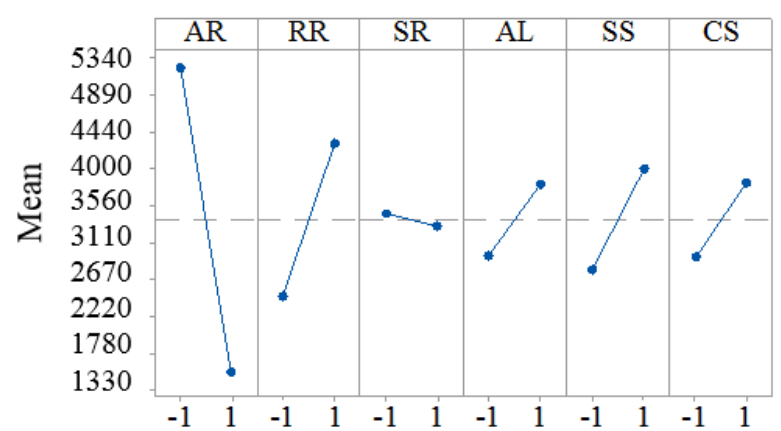

(b) $V_{p}(\mathrm{kN})$

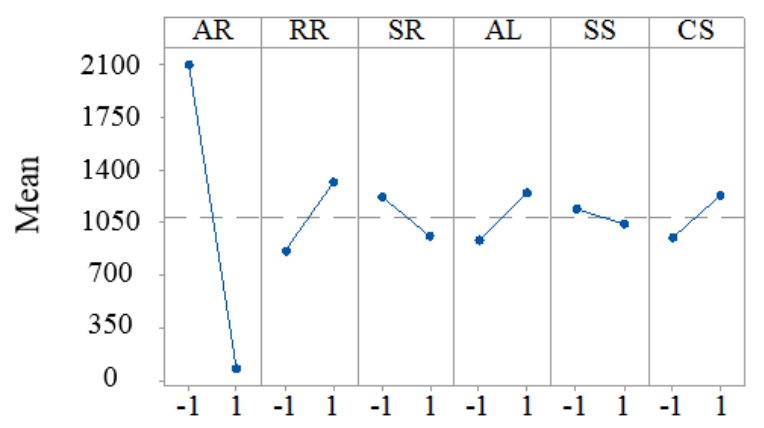

(d) $K_{p}(\mathrm{kN} / \mathrm{mm})$

Figure 4. Main effect plots of design variables 


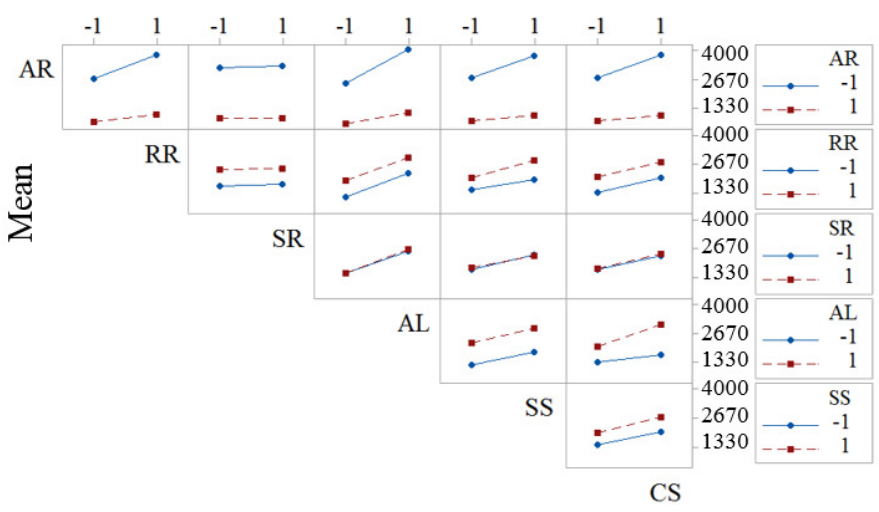

(a) $V_{y}(\mathrm{kN})$

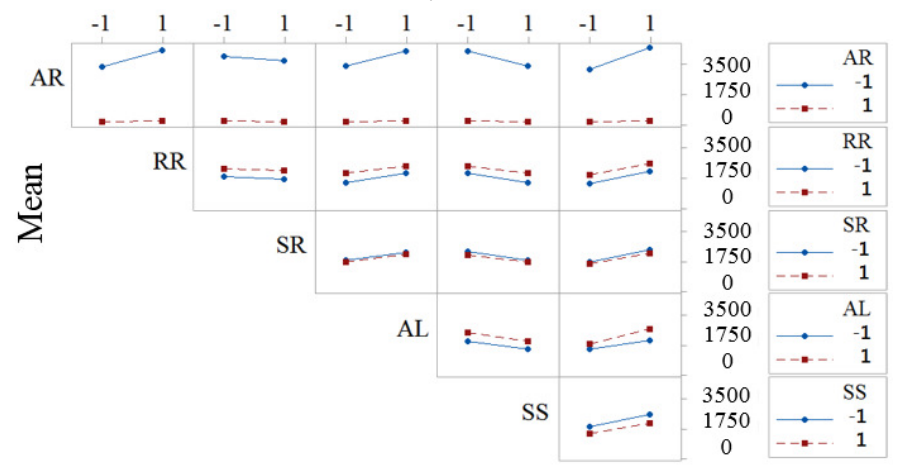

CS

(c) $K_{y}(\mathrm{kN} / \mathrm{mm})$

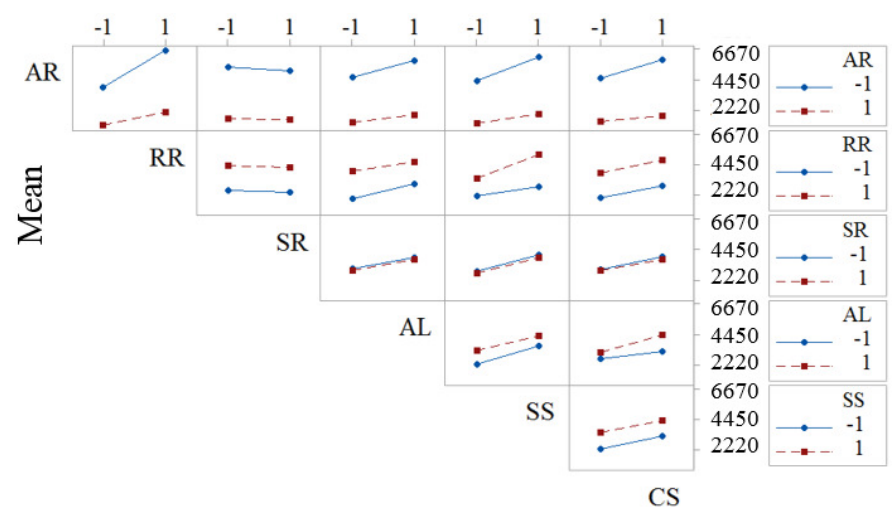

(b) $V_{p}(\mathrm{kN})$

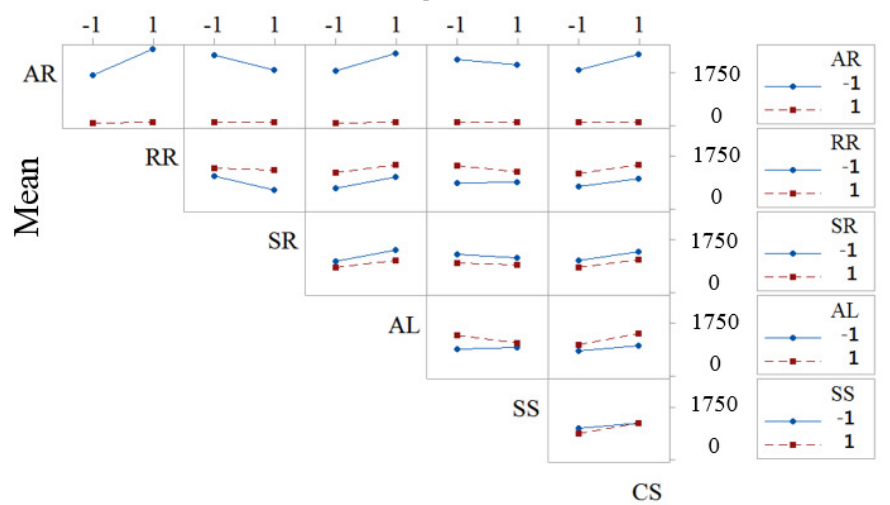

(d) $K_{p}(\mathrm{kN} / \mathrm{mm})$

Figure 5. Interaction plots of design variables 
Shear force, $V$

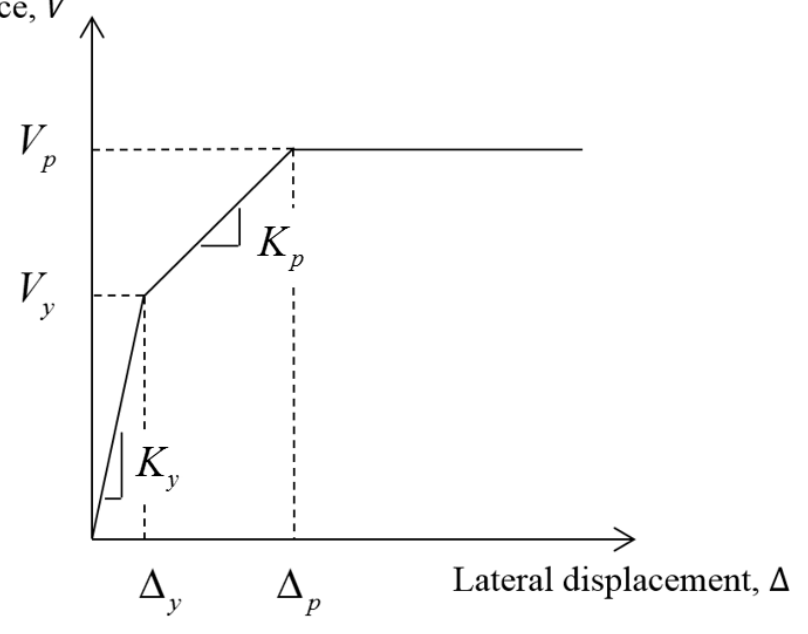

Figure 6. Tri-linear shear force-displacement relationship 

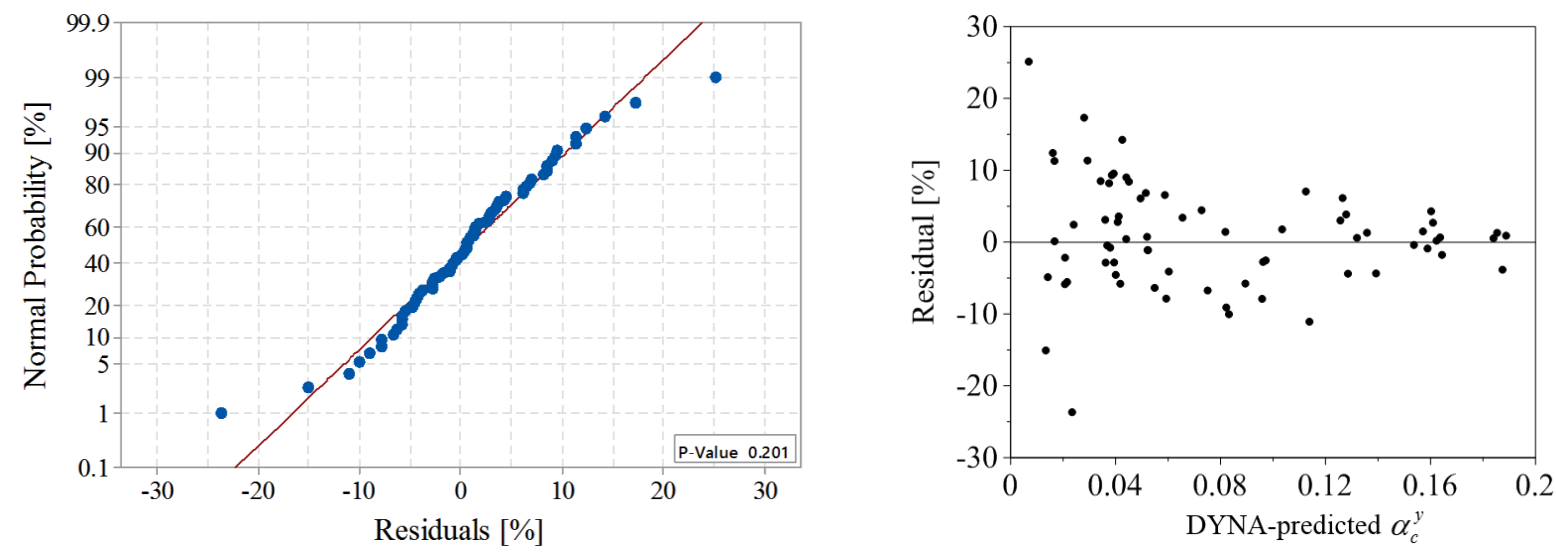

(a) Response factor $\alpha_{c}^{y}$
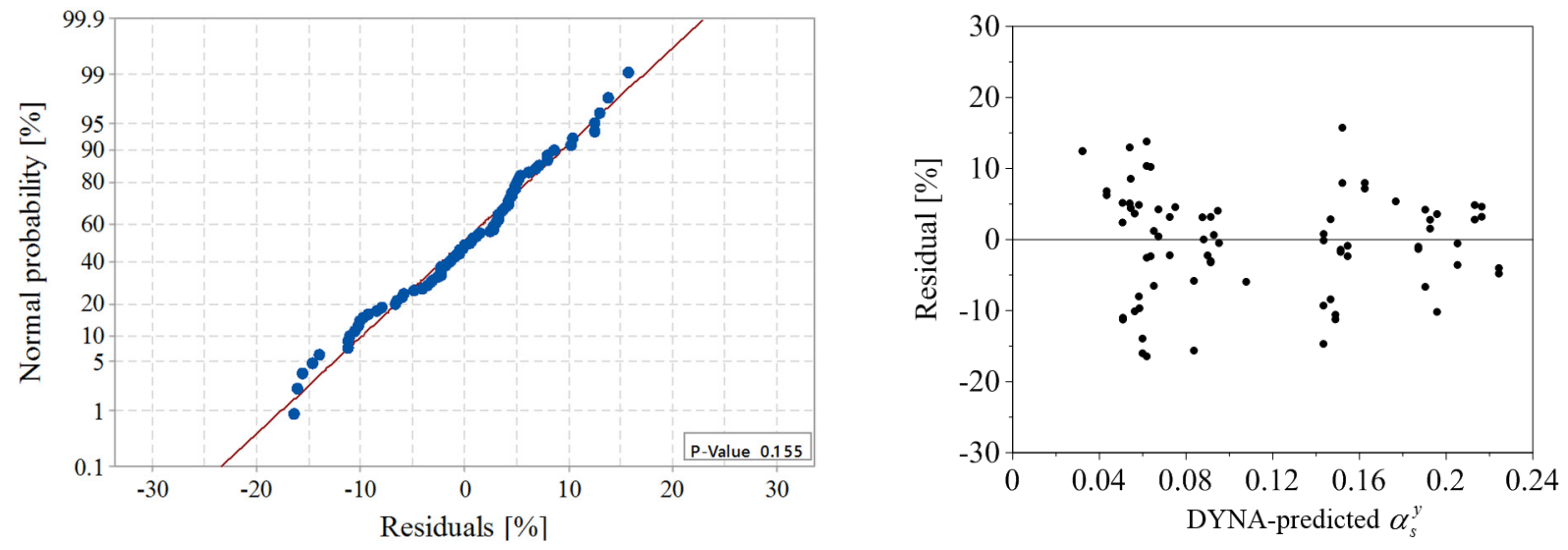

(b) Response factor $\alpha_{s}^{y}$
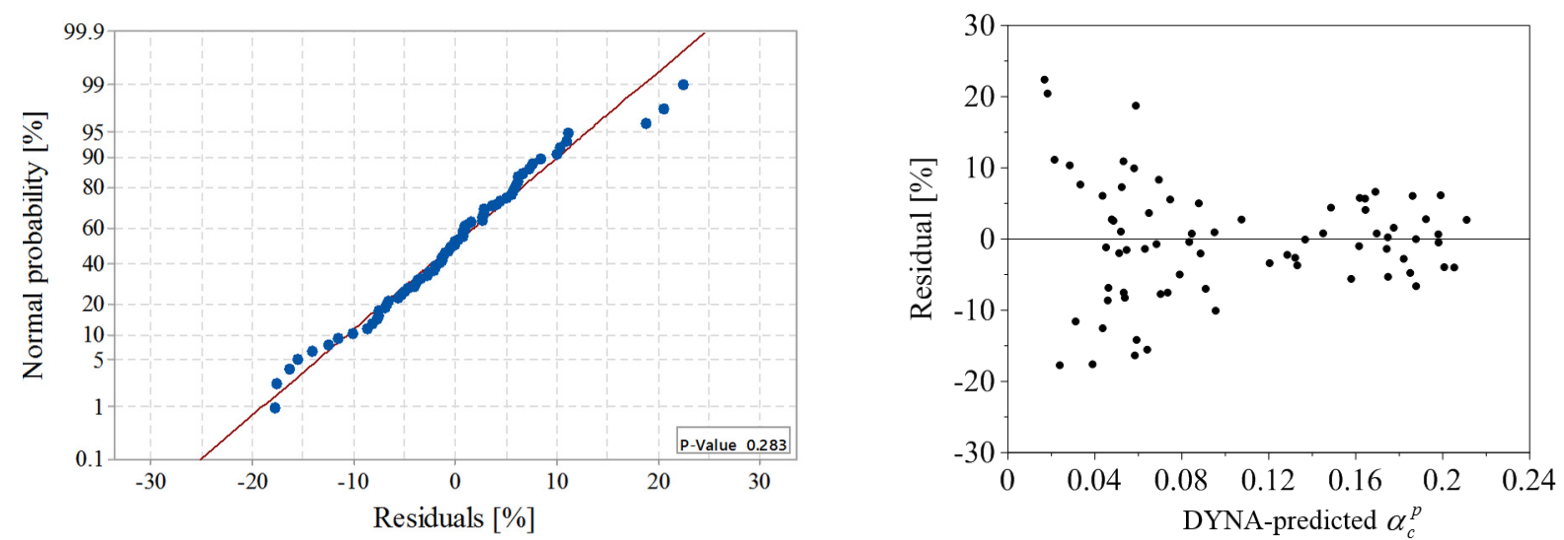

(c) Response factor $\alpha_{c}^{p}$

Figure 7. Plots of normal probability versus residual (left) and residual versus LS-DYNApredicted response variable (right) 

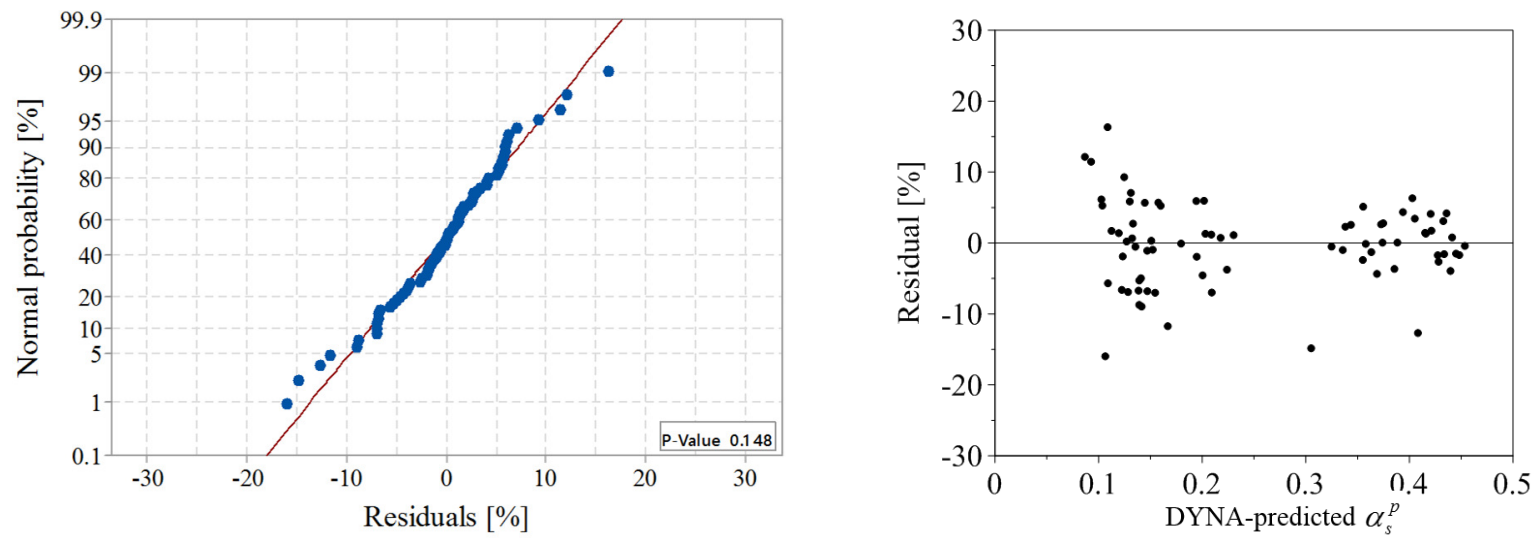

(d) Response factor $\alpha_{s}^{p}$
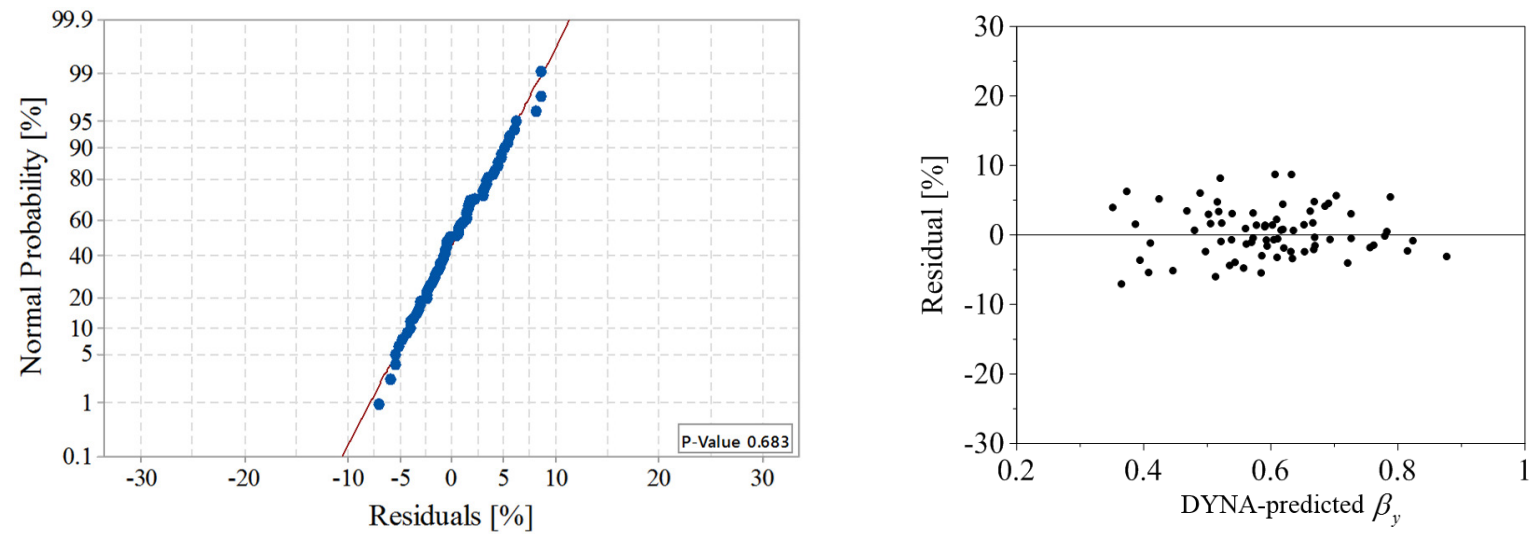

(e) Response factor $\beta_{y}$
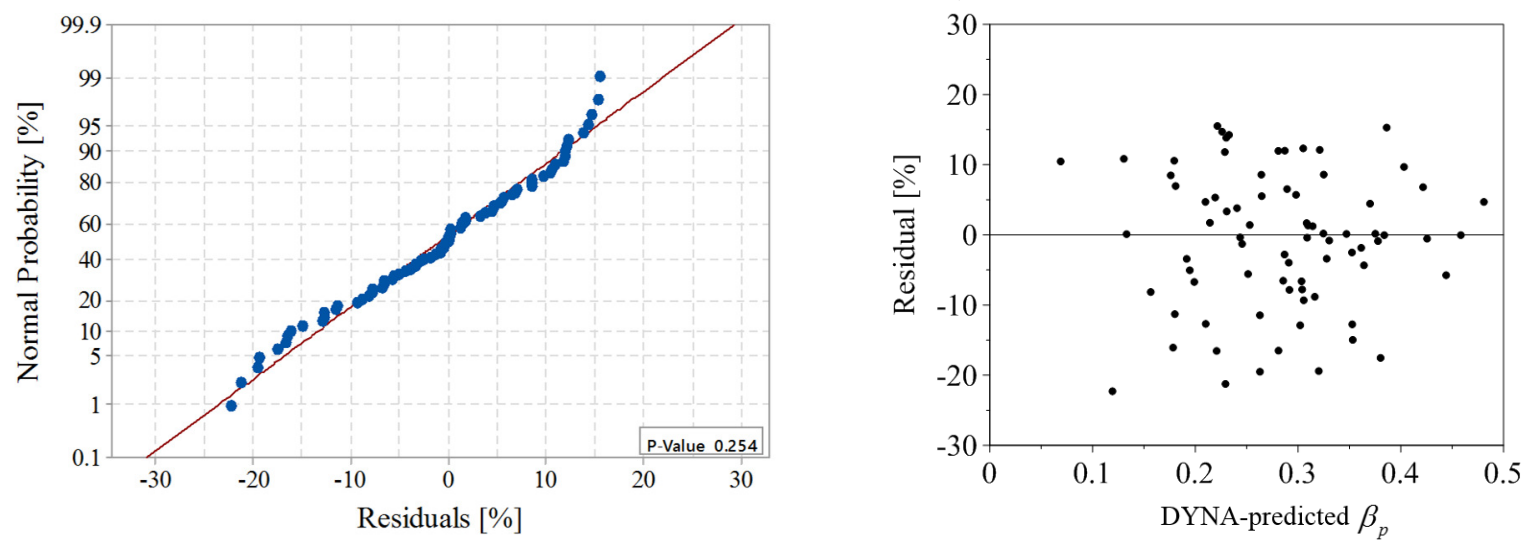

(f) Response factor $\beta_{p}$

Figure 7. Plots of normal probability versus residual (left) and residual versus LS-DYNApredicted response variable (right), cont. 


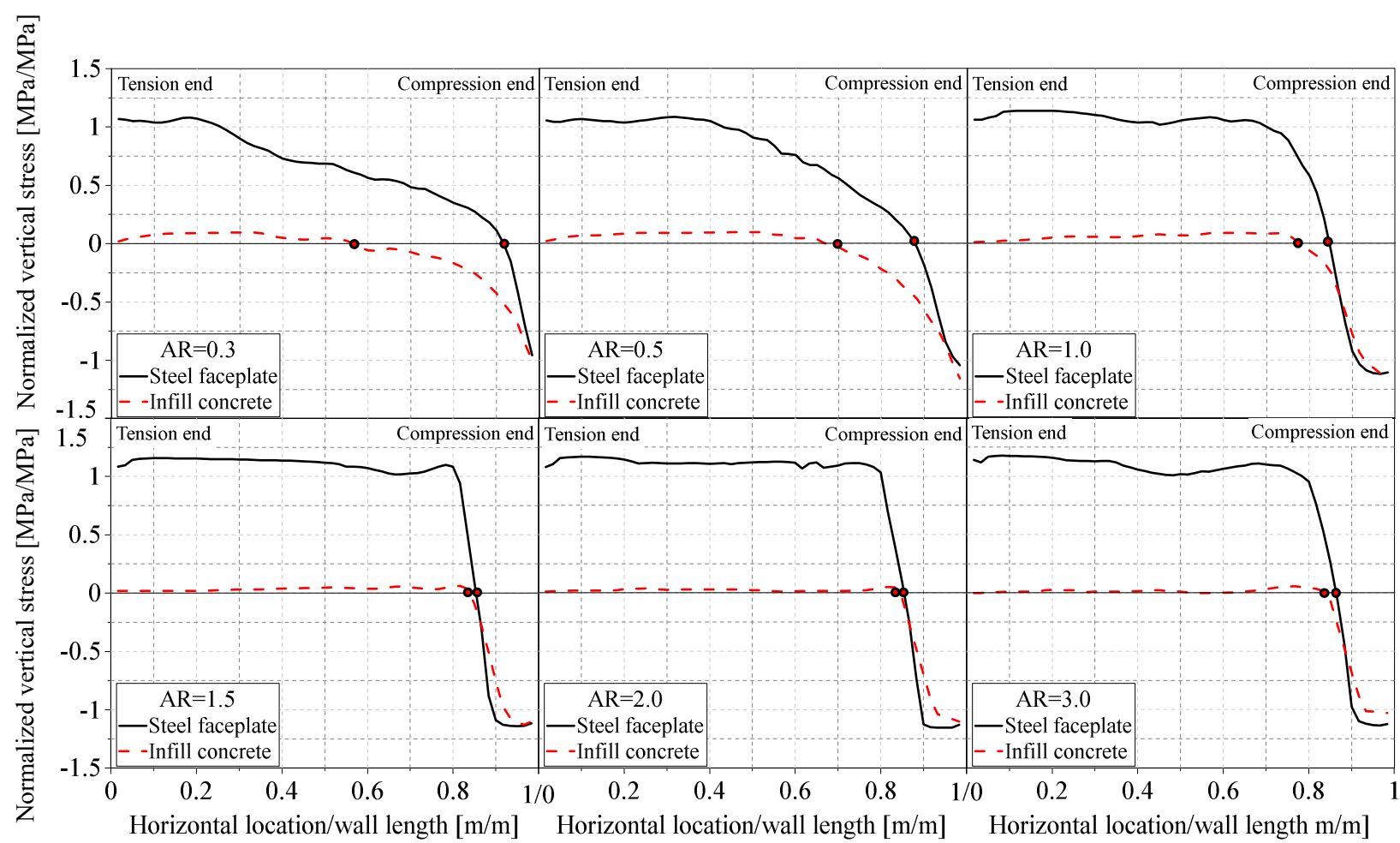

Figure 8. DYNA-predicted normal stress in steel faceplates and infill concrete at peak lateral load for zero axial load, $f_{c}^{\prime}=27.5 \mathrm{MPa}, f_{y}=260 \mathrm{MPa}$ 


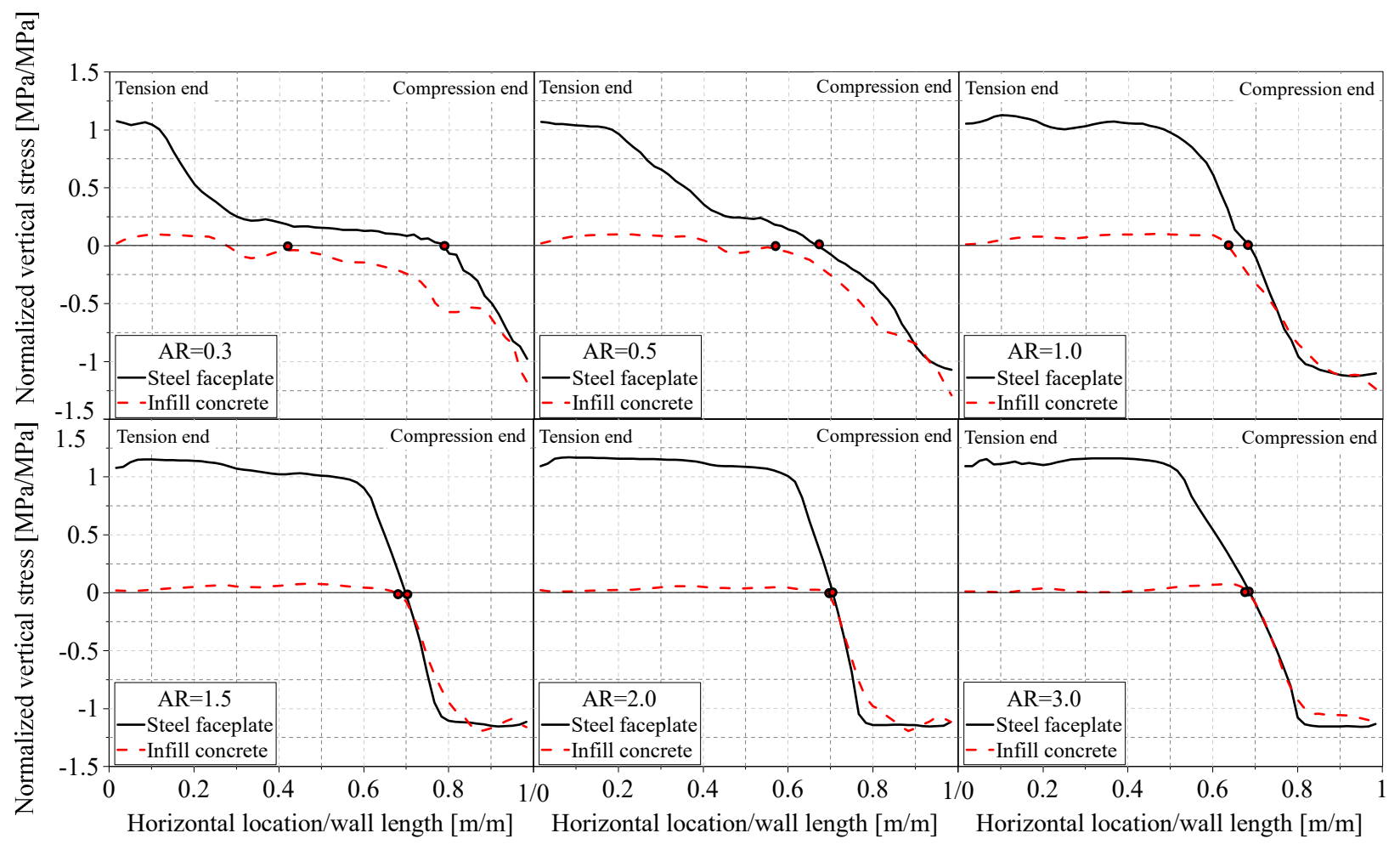

Figure 9. DYNA-predicted normal stress in steel faceplates and infill concrete at peak strength for an axial load ratio of $0.2, f_{c}^{\prime}=27.5 \mathrm{MPa}, f_{y}=260 \mathrm{MPa}$ 


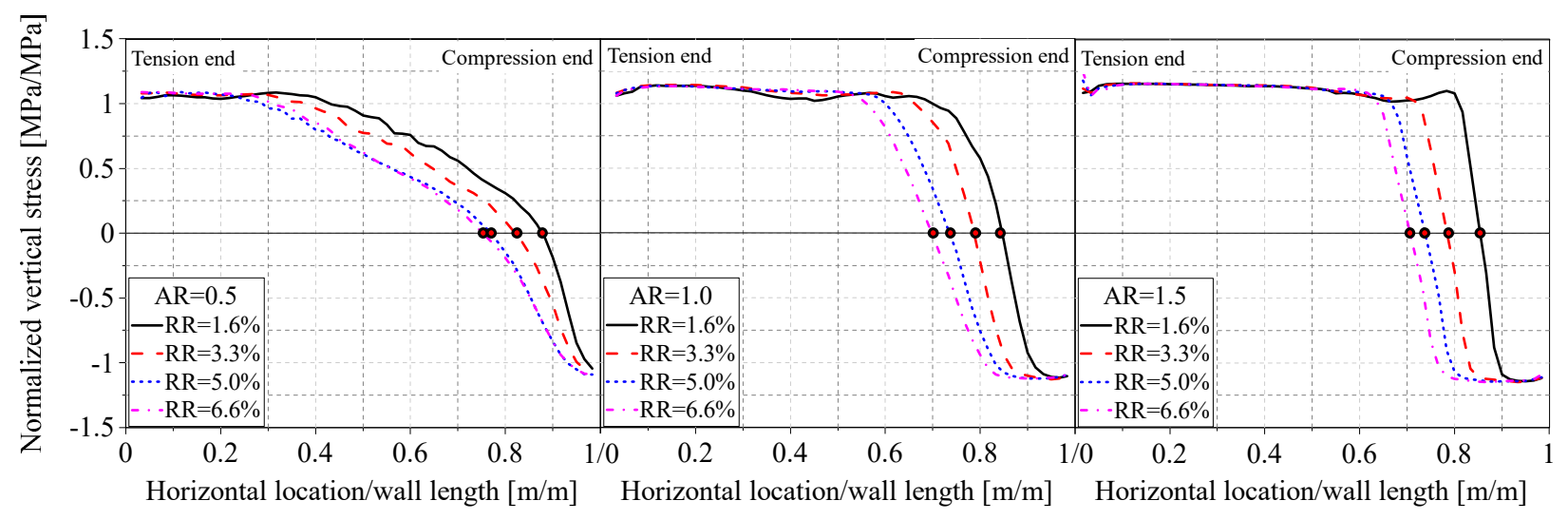

Figure 10. Effect of reinforcement ratio on the steel and concrete normal stress profiles at the wall base 


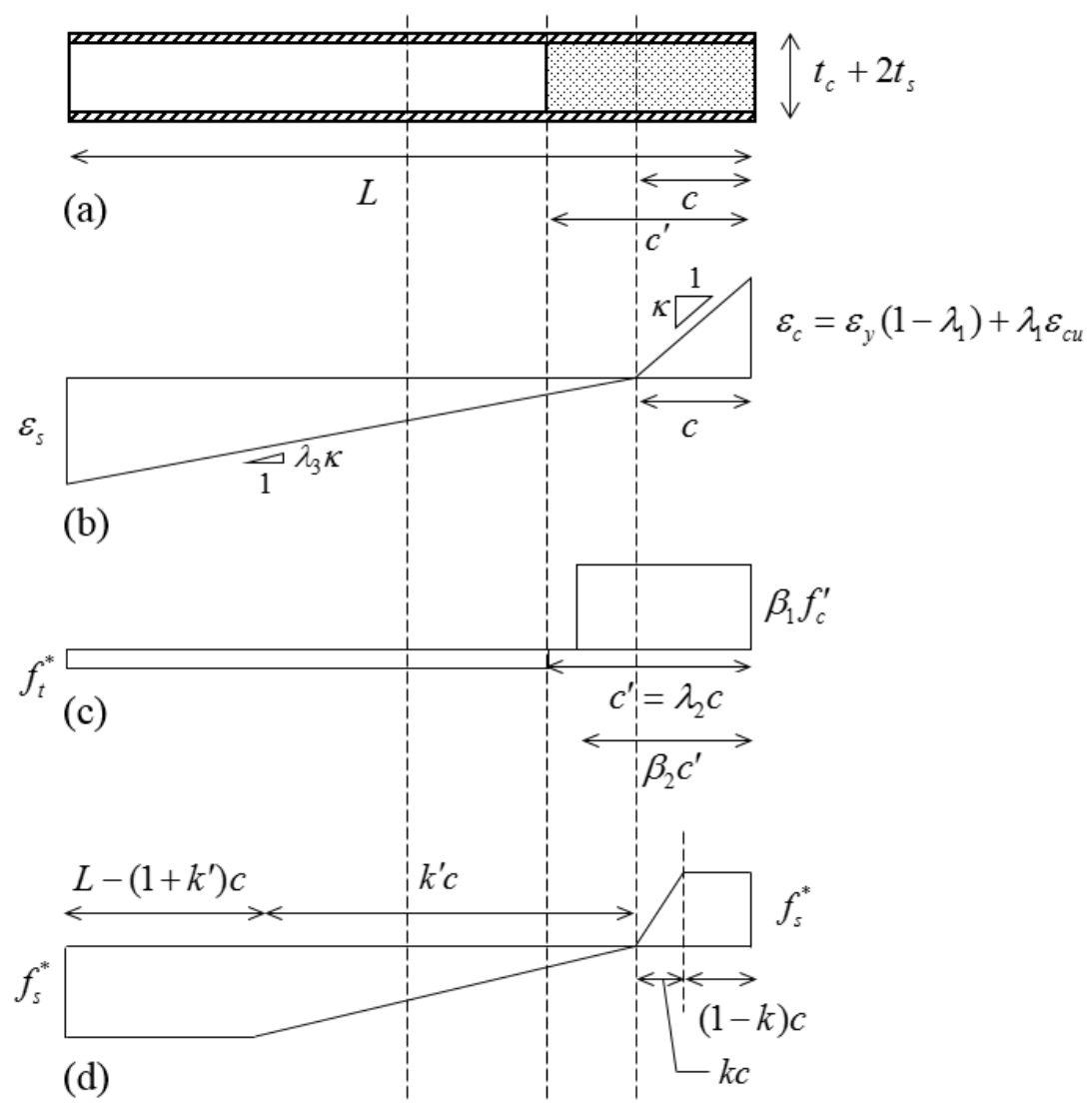

Figure 11. Moment capacity calculation; (a) SC wall cross section; (b) vertical strain profile; (c) vertical stress profile in infill concrete; and (d) vertical stress profile in steel faceplates 


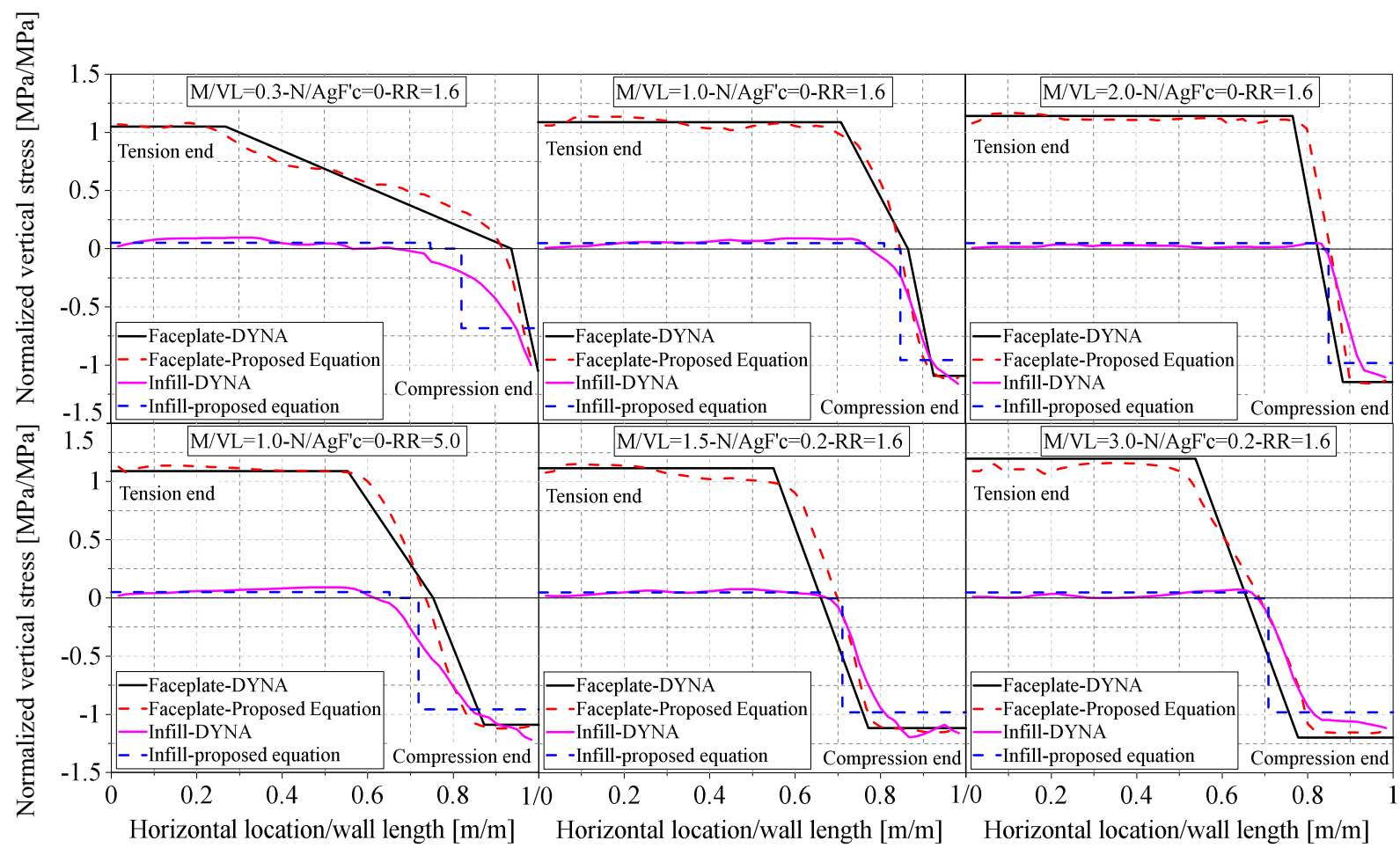

Figure 12. LS-DYNA and model predicted responses 


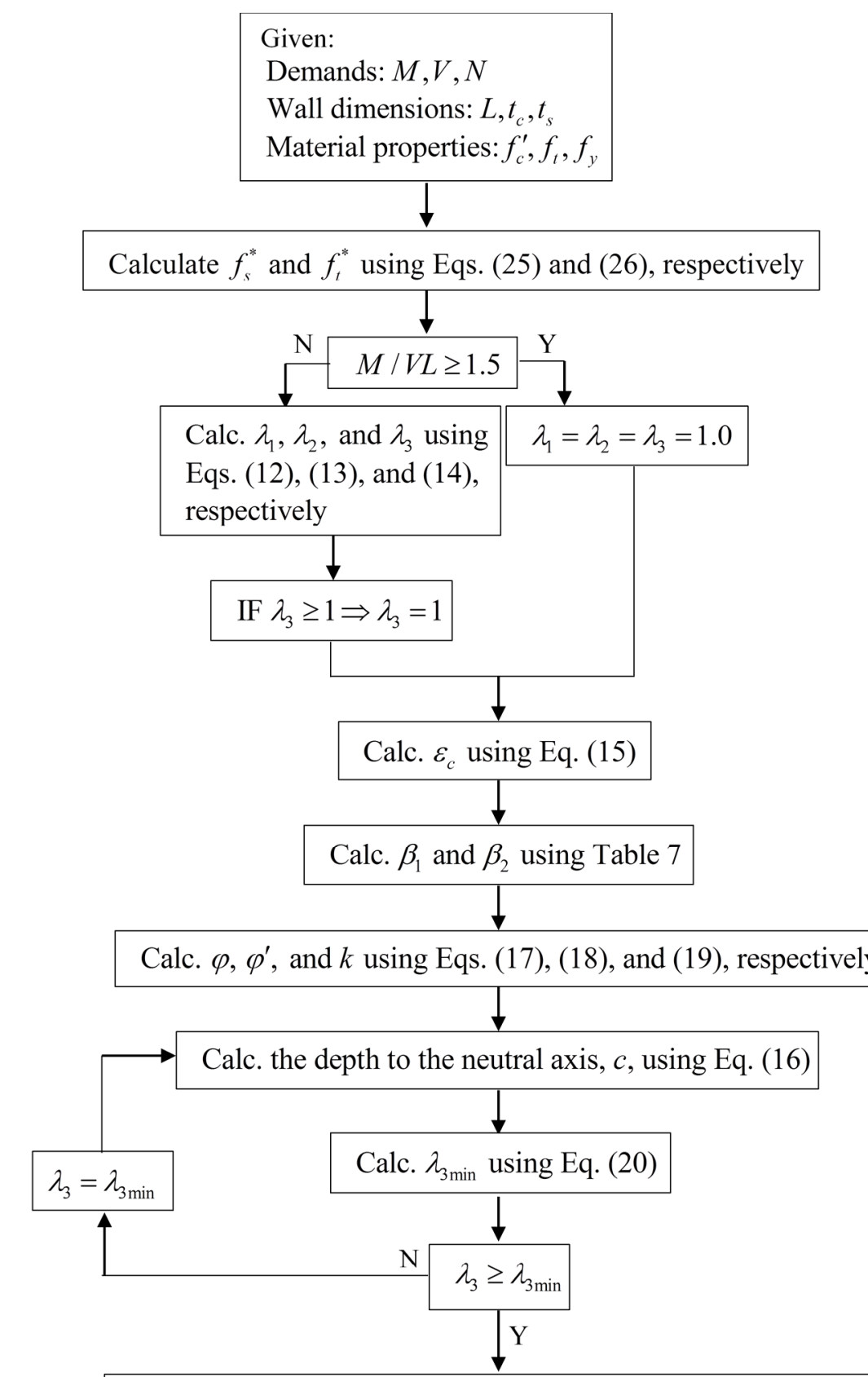

Calc. $L_{c}, L_{c}^{\prime}$, and $L_{s}$ using Eqs. (22), (23), and (24), respectively

Calc. the bending moment capacity of SC wall cross - section, $M_{u}$, using Eq. (21)

Calc. the lateral load capacity of SC wall,$V_{u}$, using Eq. (27)

Figure 13. Lateral load capacity calculation for SC wall piers 


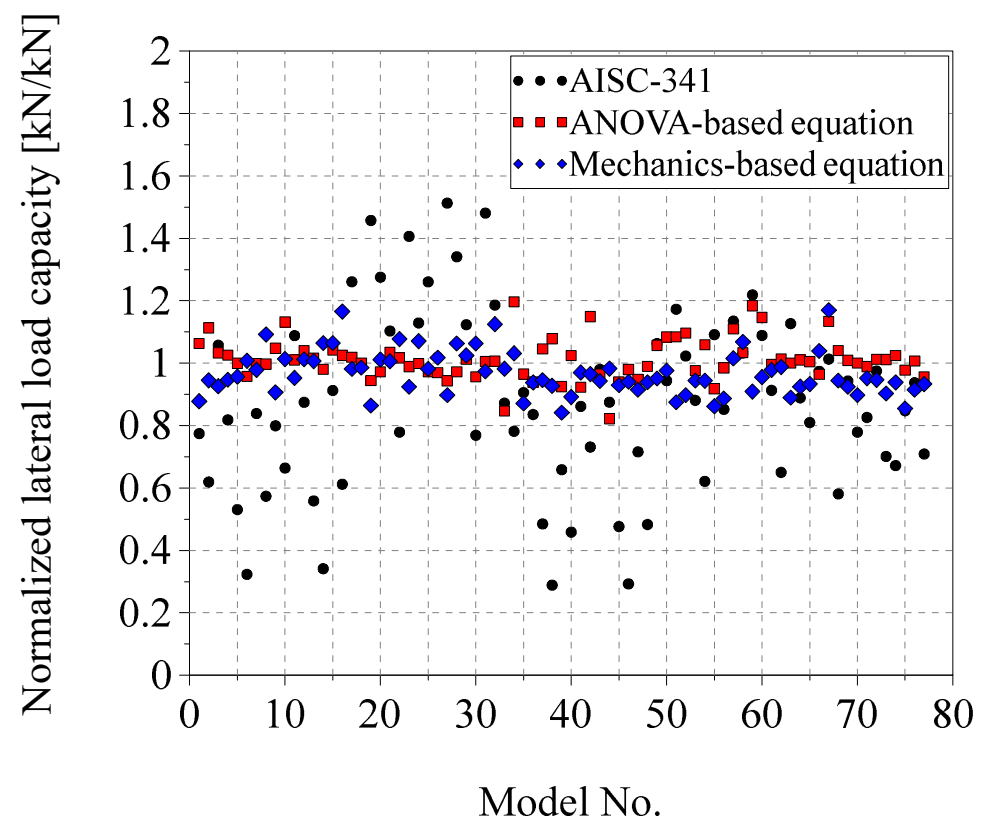

Figure 14. Predicted normalized lateral load capacity of the SC walls 


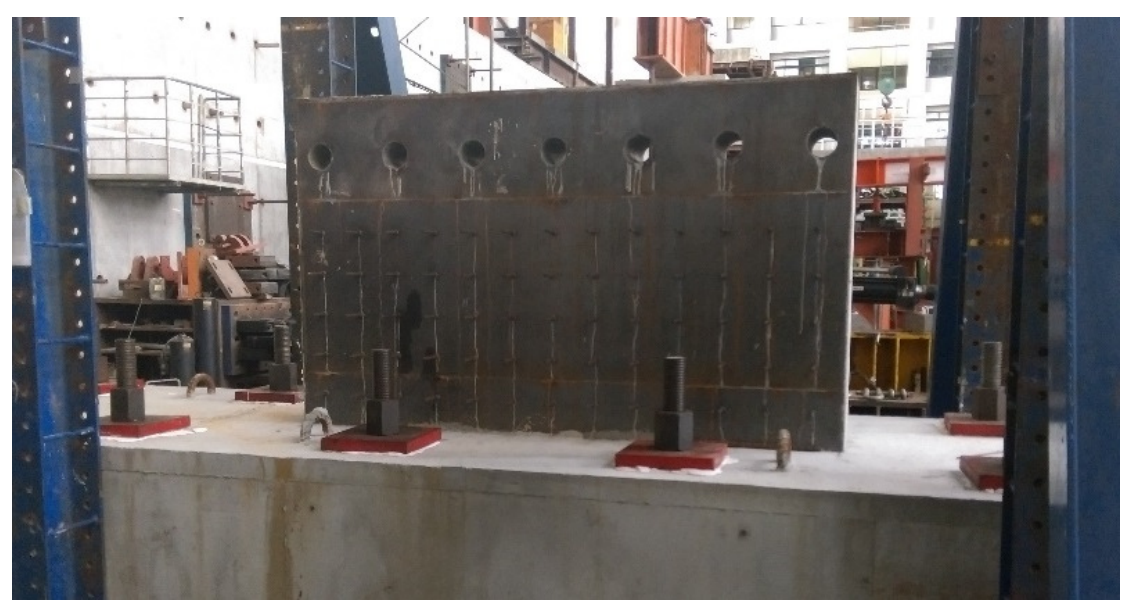

Figure 15. SC1 specimen before the test [10] 


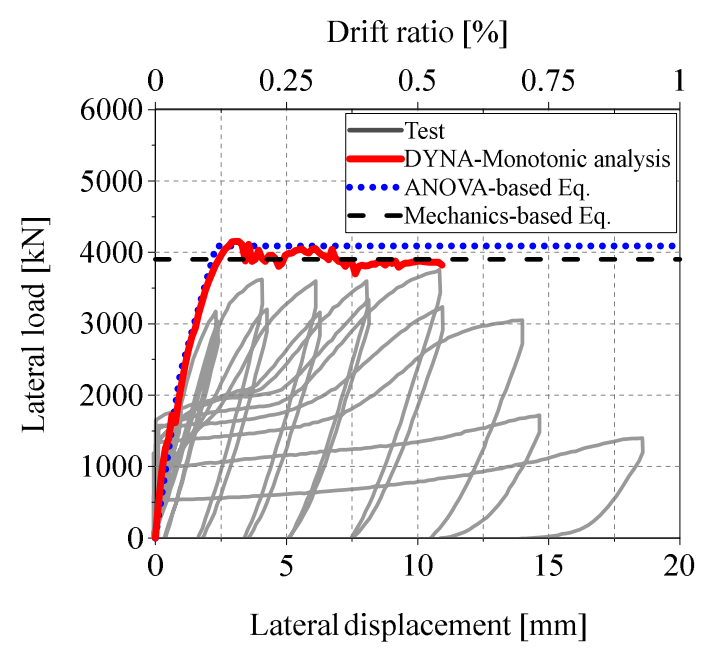

(a) $\mathrm{SC} 1$

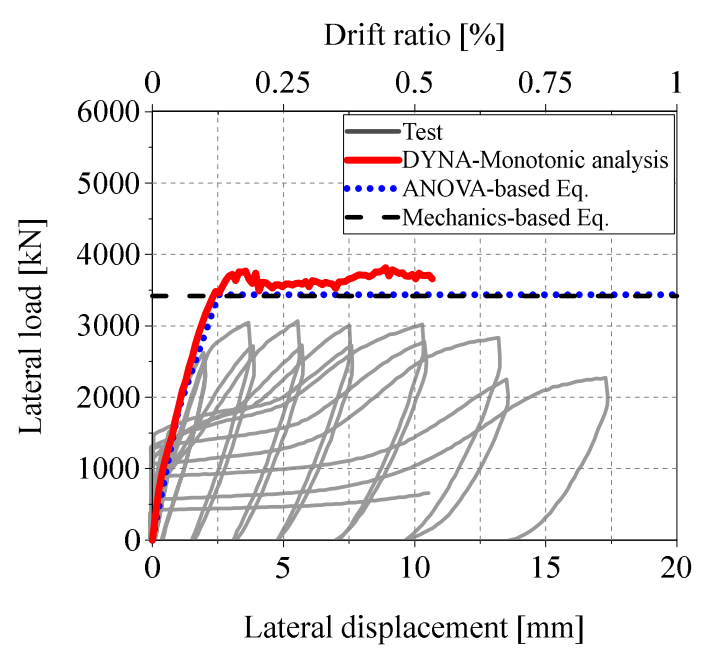

(c) $\mathrm{SC} 3$

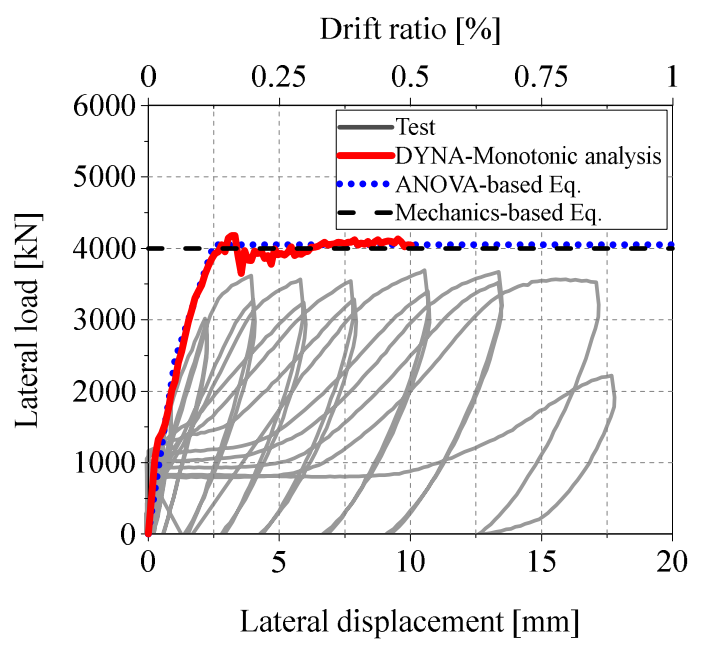

(a) $\mathrm{SC} 2$

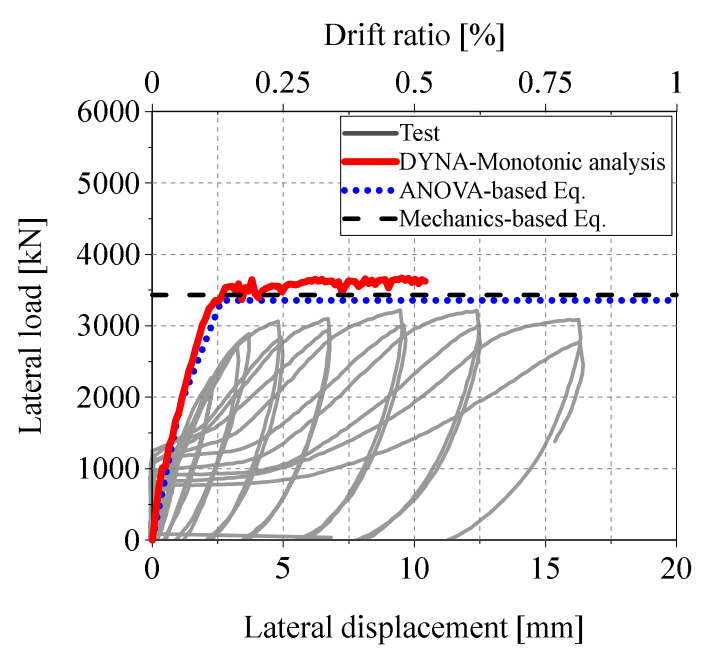

(d) $\mathrm{SC} 4$

Figure 16. Predicted and measured responses of the SC walls 
Figure 1. Stress-strain relationships for the steel material

Figure 2. LS-DYNA model
(a) aspect ratio of 0.5
(b) aspect ratio of 1.0
(c) aspect ratio of 2.0

Figure 3. Three factor factorial design

(a) Two level full factorial design

(b) Three level face-centered central composite design

(c) Three level full factorial design

Figure 4. Main effect plots of design variables

Figure 5. Interaction plots of design variables

(a) $V_{y}(\mathrm{kN})$

(b) $V_{p}(\mathrm{kN})$

(c) $K_{y}(\mathrm{kN} / \mathrm{mm})$

(d) $K_{p}(\mathrm{kN} / \mathrm{mm})$

Figure 6. Tri-linear shear force-displacement relationship

Figure 7. Plots of normal probability versus residual (left) and residual versus LS-DYNApredicted response variable (right)

(a) Response factor $\alpha_{c}^{y}$

(b) Response factor $\alpha_{s}^{y}$

(c) Response factor $\alpha_{c}^{p}$

(d) Response factor $\alpha_{s}^{p}$

(e) Response factor $\beta_{y}$

(f) Response factor $\beta_{p}$

Figure 8. DYNA-predicted normal stress in steel faceplates and infill concrete at peak lateral load for zero axial load, $f_{c}^{\prime}=27.5 \mathrm{MPa}, f_{y}=260 \mathrm{MPa}$

Figure 9. DYNA-predicted normal stress in steel faceplates and infill concrete at peak strength for an axial load ratio of $0.2, f_{c}^{\prime}=27.5 \mathrm{MPa}, f_{y}=260 \mathrm{MPa}$ 
Figure 10. Effect of reinforcement ratio on the steel and concrete normal stress profiles at the wall base

Figure 11. Moment capacity calculation; (a) SC wall cross section; (b) vertical strain profile; (c) vertical stress profile in infill concrete; and (d) vertical stress profile in steel faceplates

Figure 12. LS-DYNA and model predicted responses

Figure 13. Lateral load capacity calculation for SC wall piers

Figure 14. Predicted normalized lateral load capacity of the SC walls

Figure 15. SC1 specimen before the test [10]

Figure 16. Predicted and measured responses of the SC walls
(a) $\mathrm{SC} 1$
(b) $\mathrm{SC} 2$
(c) $\mathrm{SC} 3$
(d) $\mathrm{SC} 4$ 